\title{
The Evaluation of the Food Industries in Nigeria between 2010 and 2015*
}

\section{Dr. Asmaa Ghieth**}

Agriculture remains largely subsistence-based, and about $80 \%$ of the agricultural output comes from farmer activities of those life, in Nigeria, on less than a dollar per day as farming less than one hectare (FAO, 2017). According to the FAOSTAT data provided in 2016, the crop production accounts for about $85 \%$ of all agricultural activities, while livestock and poultry participate with $10 \%$ to leave almost $5 \%$ to fisheries and forestry activities.

Nigeria imported a large volume of agriculture raw materials between 1995 and 2012 estimated as \$ 71,472.641 and 905,272.931 respectively, and the amount of food basic productsincreased from $\$ 903,923.52$ in 1995 to be \$ 963, 998, 9.6 in 2012 (ECDPM, 2015, p. 42).

In the light of the above and according to the shortage of infrastructure that the country witnessed, the agriculture food basic products were burdened the country budget more than the food raw materials, agriculture products hundred

* This chapter is part of my Ph.D. thesis.

** Businesses consultant and GIS professional expert.

For Correspondence: e-mail: asmaa1ghieth@gmail.com 
times since 1995. The amount in USD in 2012 of food products imported into Nigeria reflects that the country is still underdeveloped in the food processing sector as per observation. However, the country imported agriculture technologies, machines, and food processing technologies also to improve its volume of food crop productions and saving food waste, it seems that the initial phase of food processing as a post-harvested step in Nigeria starts to be developing. The previous imported bills mirrored the increases in the total cost of the food production. Urbanization growth leads to high demand for the food processed products where the high trends of services activities are in change.

The structure of food manufacturing relies on changing consumption patterns that affected by three main factors as; purchasing power, income rates, and lifestyle. Due to the food market analysis conducted by (KPMG, 2015), it seems that the populations in Nigerian urban areas are continuing to shift toward convenience food consumption habits. The high demand for fast food products leads to an increase in the performance of fast-food manufacturing processors as a consequence. Furthermore, the factories that process dried, frozen, and canned food, since the rural areas still the main fresh poultry suppliers to the urban areas.

\section{The Food Industrial Structure between 2010 and 2015}

\subsection{The diagnosis analysis of $F \&$ B shares in GDP}

The manufacture structure in Nigeria consists of 13 activities, Oil Refining, Cement, Food \& Beverage, Tobacco, and others. (NBS, Nigerian Gross Domestic Production report, 2016, p. 10). The formal manufacturing sector dominated by output from the Food, Beverage, and Tobacco, as it shares the greatest contributors in the Nigerian manufacturing sector between 2010 and 2015. According to the GDPs in the referred period, Food and Beverages (F \& B) and Tobacco reached a share of $72.02 \%$ out of the total manufacturing Sub-sectors in 2010. This shared value declined in 2013 to $52.74 \%$, thereafter a portion of $45.55 \%$ deceased again in 2015 to form $4.56 \%$ of the GDP in the same year.

Despite F \& B shown growth in the manufacturing sector, its share witnessed decline in the total GDP between 2013 and 2015 after it increased between 2010 and 2012. The rationale behind that returned to the food Subsector ongoing challenges including inadequate electricity supply, as mentioned before, with fluctuated prices of fuel, poor infrastructure, and lacking in the plant maintenance. The sector plagued by the deteriorated operations on the macro level as a backdrop, and the degrading impacts the foreign exchange. The share output in the total manufacturing activities declined gradually since 2010, but the portion in GDP fluctuated to decline from 2013 until 2015. 


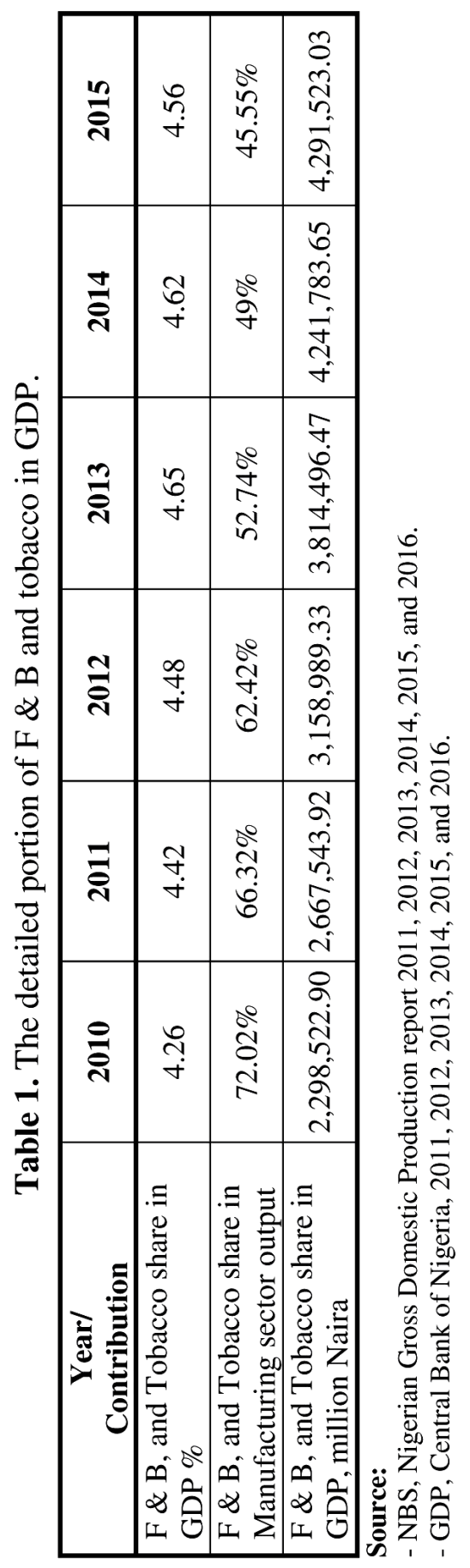

$-5-$ 
The statistics of Food, Beverages and Tobacco manufacturing status between 2010 and 2012 illustrates that four products were dominated the food manufacturing, while three products controlled the beverage productions. Those four products topped by Sugar manufacturing followed by bread, Biscuit, and then rice processing. Table (2) shown that sugar manufacturing is dominating the food processing. NBS published that the growth of sugar output was higher than the sector average in 2011, and increased by $497,902.73$ million Naira or $25.66 \%$, driving the majority of growth in the sector in the same year. With the growth of 271,968.03 million Naira, or $11.15 \%$, the size of sugar output marked that it largely contributes to the growth of the following year also. The development of sugar refining output was higher than the total average of the foodmanufacturing sector as recorded by about $32 \%$, as it drivesthe majority of the progress between 2013 and 2015. (NBS, 2017, p. 10).

As observed from data given in table (2), the first three manufacturing Sub-classes contributing are more related to one another, as Biscuit depends mainly on two inputs as flourand sugar. While bread production processing is relay on flour mill output as same as pasta and noodle are depending on the same flour products, confectionery based on sugar products. In fact, sugar refining is a cornerstone manufacturing to support different production of the food, drug, beverages, and tobacco processing. This clearly shown in the growth of the beverages manufacturing in the same period, since the top three beverages Sub-manufacturing categories were wine, alcoholic drinks, and beer. Those are followed by soft drinks and juice that using sugar in the processing phase.

Although the bread Sub-sector has shown fluctuation stir, it presented as an important contributor to the manufacturing sector before rice milling, and its share was $22.72 \%$ in 2013 and about $30.21 \%$ in 2015. Despite the Biscuit manufacturing has more phases than rice milling, the output from rice milling values jumped over the Biscuit. Biscuits manufacturing with its related processing represented $7.18 \%$ of the total $\mathrm{F} \& \mathrm{~B}$ manufacturing portion in 2010 . This share increased by almost $1.8 \%$ every two years to be $8.32 \%$ in 2013 , and $10.42 \%$ in 2015 of total F \& B manufacturing shares. Rice padded stood at $10.32 \%$ in 2010, and $12.56 \%$ in 2013 there after increased to be $15.2 \%$ in 2015 of total Food manufacturing output value. Both rice and biscuits outputs presented a stable growth rate between 2010 and 2015 paralleled with the growing population and the resulted local demand to sustain their production as per market needs. 
Table 2. Food, Beverages and Tobacco Sub-classes share between 2010 and 2012.

\begin{tabular}{|c|c|c|c|c|}
\hline $\begin{array}{c}\text { Food, Beverages } \\
\text { and Tobacco } \\
\text { Sub-sector }\end{array}$ & Year & $\begin{array}{c}\text { Value in } \\
\text { Million Naira }\end{array}$ & $\begin{array}{l}\text { Percentage of } F \\
\& B \text { and Tobacco } \\
\text { manufacturing }\end{array}$ & $\begin{array}{c}\text { Percentage of } \\
\text { total } \\
\text { manufacturing } \\
\text { sector }\end{array}$ \\
\hline \multirow{5}{*}{ Sugar } & 2010 & $1,940,413.34$ & 39.36 & 28.35 \\
\hline & 2011 & $2,438,316.12$ & 44.99 & 29.84 \\
\hline & 2012 & $2,710,304.15$ & 44.20 & 27.59 \\
\hline & 2013 & - & 46 & - \\
\hline & 2015 & - & 52.3 & - \\
\hline \multirow{5}{*}{ Bread } & 2010 & $1,398,459.12$ & 28.36 & 20.43 \\
\hline & 2011 & $1,099,934.59$ & 20.30 & 13.46 \\
\hline & 2012 & $1,319,418.19$ & 21.52 & 13.43 \\
\hline & 2013 & - & 22.7 & - \\
\hline & 2015 & - & 30.21 & - \\
\hline \multirow{3}{*}{ Juice } & 2010 & 120157.13 & - & - \\
\hline & 2011 & $303,015.41$ & - & - \\
\hline & 2012 & $341,070.37$ & - & - \\
\hline \multirow{5}{*}{ Rice } & 2010 & $508,720.13$ & 10.32 & - \\
\hline & 2011 & $681,562.84$ & 12.58 & 33.98 \\
\hline & 2012 & $760,719.92$ & 12.41 & 11.61 \\
\hline & 2013 & - & 12.56 & - \\
\hline & 2015 & - & 15.2 & - \\
\hline \multirow{5}{*}{ Biscuits } & 2010 & $353,836.08$ & 7.18 & - \\
\hline & 2011 & $453,807.45$ & 8.37 & - \\
\hline & 2012 & $503,679.49$ & 8.21 & - \\
\hline & 2013 & - & 8.32 & - \\
\hline & 2015 & - & 10.42 & - \\
\hline
\end{tabular}

Source:

- NBS, Nigerian Manufacturing Sector, Summary report; 2010-2012.

- CBN, Annual report-financial Sector development; 2016.

The second factor of this F \& B sector booming is the availability of the local sourced inputs, and the most important factor is the huge domestic demand. This high market need considers as the great potential for future expansion that pushing the processing performance, as a resulted of the oil thrived production between 2000 and 2015 .

Although the new organizations that entered into the $\mathrm{F} \& \mathrm{~B}$ manufacturing field were multinational processors, the field witnessed an expansion of the existing operators as large multinational food companies as 
Nestle, Cadbury, and Coca Cola. Those large size food processors are performing to produce rapidly in the last three decades, and controlling the trend of food manufacturing particularly in their specializations. While Nigeria imported foodstuff in 2013 as reported in Table (3), the local manufacturing Sub-sector tried to rise their production to control the local market.

Table 3. Distribution of Imported food and beverages Productions by categories in percentage, year 2013.

\begin{tabular}{|l|c|}
\hline \multicolumn{1}{|c|}{ Food Processing Sub-Sector by Categories } & Proportion (\%) \\
\hline Flour & 19 \\
\hline Vegetable Oil/Fat & 16 \\
\hline Alcoholic Beverages & 15 \\
\hline Non-Alcoholic Beverages & 14 \\
\hline Bread/Snacks & 7 \\
\hline Rice & 8 \\
\hline Dairy/Milk Powder Re-composition, Canning \& Packaging & 4 \\
\hline Sugar Refining & 6 \\
\hline Cookies/Crackers (Biscuits) & 4 \\
\hline Pasta & 3 \\
\hline Confectionery & 2 \\
\hline Others & 2 \\
\hline \multicolumn{2}{|c|}{ Total } \\
\hline
\end{tabular}

Source: GAIN report, 2014.

\subsection{The Status of Food and Beverages Manufacturing between 2010 and 2015}

To evaluate the current operating manufacturing organizations, the candidate used the data listed in the Nigerian-American Chamber of Commerce and the Federal Ministry of Industry, Trade and Investment together for ensuring the quality of data and the resulted evaluation.

\subsubsection{The Manufacturing of Grain Mill Products}

The grain mill production increased in 2010 after the implemented policy of maximizing the utilization of local grains. Since 2009, new policies started to adapt and it impacting agriculture production as it changed as a result. The total utilizing capacity in 2008 was $42 \%$ and the producers sustained this share in 2009 before an experienced increase in 2010 to perform reached $76.97 \%$ of the total local manufacturing capacity. The grain production increased consequently, which pushed the factories to utilize more capacity throughout the country to $80.47 \%$ in 2011 . 
Although the manufacturing operated less in 2012 to employ only $42.81 \%$ of their total capacity, the subsidies of fuel were pushed to run operations in 2013.

Consequently, it increased to be $56.91 \%$, while the local production of grains and the policies of mixed bakery productions pushed this manufacturing towards upgrading to jump as $80.41 \%$ in 2014 before reaching $90.22 \%$ in 2015 , it seems that the main grain mill producers suffered to manage their performance during the mentioned period.

Table 4: The Grain Mill products Manufacturing Capacity Utilization (Percent).

\begin{tabular}{|l|c|c|c|c|c|c|c|}
\hline Sub Sector/ Year & $\mathbf{2 0 0 9}$ & $\mathbf{2 0 1 0}$ & $\mathbf{2 0 1 1}$ & $\mathbf{2 0 1 2}$ & $\mathbf{2 0 1 3}$ & $\mathbf{2 0 1 4}$ & $\mathbf{2 0 1 5}$ \\
\hline Grain Mills Products & 42 & 76.97 & 80.47 & 42.81 & 56.91 & 80.41 & 90.22 \\
\hline
\end{tabular}

Source: CBN, annual bulletin of 2010, 2011, 2013, and 2015.

Flour Mill Nigeria (FMN) Company increased its grain mill units in 2011 to produce almost three million Mt. annually instead of 340,000 Mt. especially after it expanded its farm in Niger State (FMN annual report, 2013 , p. 3). According to Olam business operation report, since 2010, Olam acquired Crown Flour Mills at Lagos state to increase its production from 40 Mt. wheat daily to be 1,630 Mt. daily in 2011. Dangote Flour Mills between 2011 and 2014 increased its grain and flour milling operations to establish two new production subsidiaries as Noodles and Pasta factories at Lagos. It reached the output of $5000 \mathrm{Mt}$. daily of flour milling in 2014. (Dangote Group annual reports, 2012, 2013, 2014). Honeywell Superfine Flour expanded its capacity in 2010 to produce $44,000 \mathrm{Mt}$. of wheat and 72,900 Mt. of grain. The company carried out another expansion project, a twin mill facility of 1,000 Mt. daily with $500 \mathrm{Mt}$. daily mill to be completed in May 2012, while the second $500 \mathrm{Mt}$. daily mill was planned to complete by September 2012. The expansion project was complete in 2013 and production capacity became 2,610 Mt. daily (Honeywell Superfine Flour annual report, 2014, p. 9)

Due to the observation, the flour miller operation units were not increased, but it exposed to the main two changes as follows:

1. They increased their manufacturing capacity between 2010 and 2015 of flour mill.

2. They exposed to acquisition, purchased by other companies or competitors. 


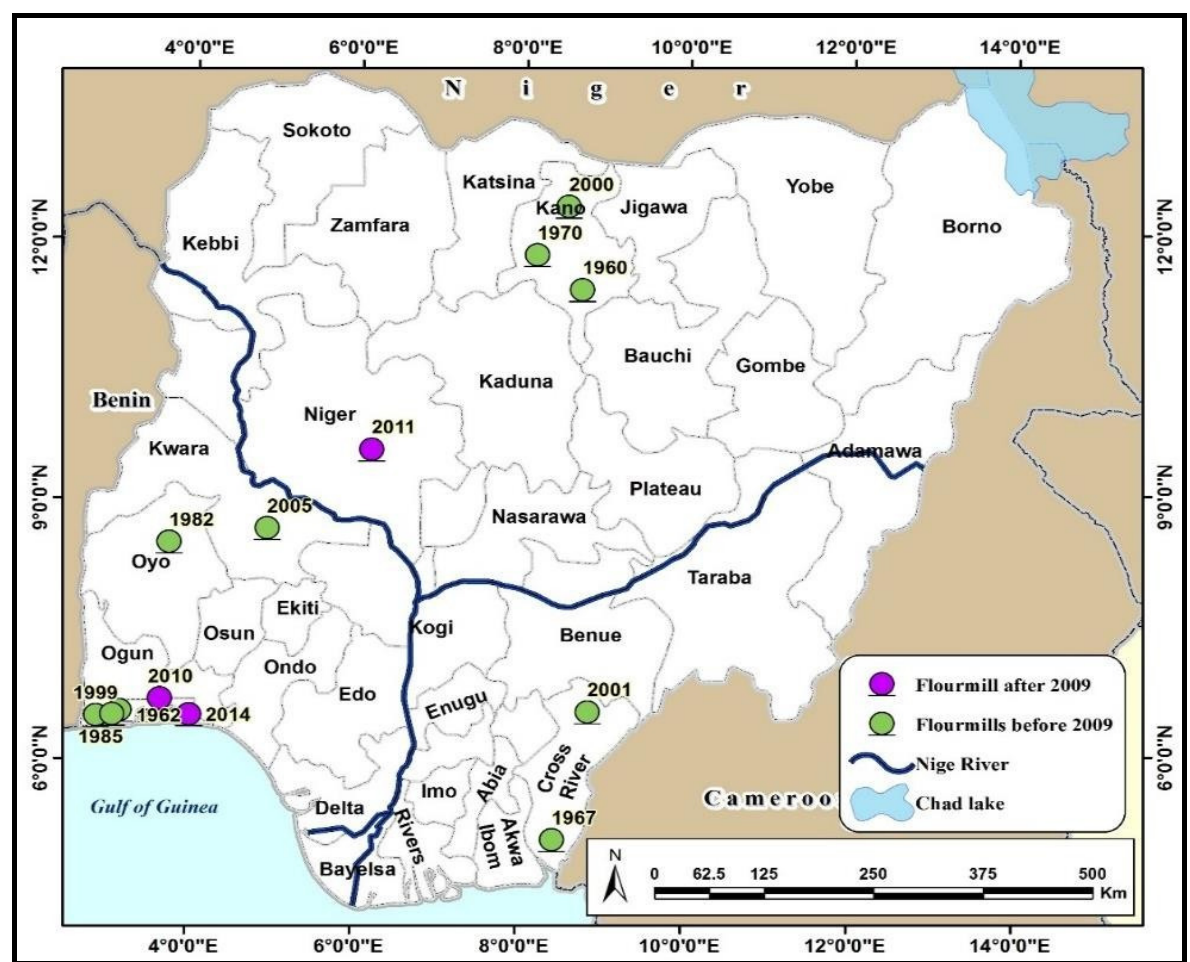

Figure 1. New flour milling units by states, between 2010 and 2015. Source: Data collected from the three large size companies expanded their business between 2010 and 2015.

Since both have got profits by increased their capacity production to supply the market and themselves to produce other goods such as pasta/macaroni, noodles, and semolina. The manufacturers did not expand in new locations for flour and grain milling operation, but they did for pasta and noodles as will be explained later. FMN preferred to expand its investments in two new states that it never experienced before, as it got a farm in Niger state in 2011, and bought 52.6\% of shares in Cross River flour plant.

\subsubsection{Manufacture of Starches and Starch Products}

The manufacturing of starches and starch products in Nigeria experienced an increase between 2009 and 2015. The given information of CBN provided that the growth of manufacturing capacity utilization increased gradually from almost $20 \%$ in 2009 to reach $37 \%$ in 2011 . The manufacturing units testified decreasing until 2015 to hit $18 \%$, as the main reason behind this percentage fluctuation was increased the operational capacity of the grain mills to produce starch in the same period. The 
manufacturing capacity increased for the favor of grainmills operators rather than starches factories. The little portion of starches manufacturing capacity testified increased. Some of the starch factories expanded their own business by cultivating their new farms of maize and cassava to supply themselves with grains to increasethe utilizing capacity.

The national demand for maize starch in Nigeria is estimated by about 800,000 tons a year, while the national supply estimated at 350,000 tons annually in 2016. (KPMG, 2017, p. 7). Since 2010 Nigerian Starch Mills organization produced 85.000 tons of starch a year, further 25,000 , and 250,000 tons annually year of both rice and cassava processing respectively sourced by Kwara state (Nigerian Starch Mills, 2018).

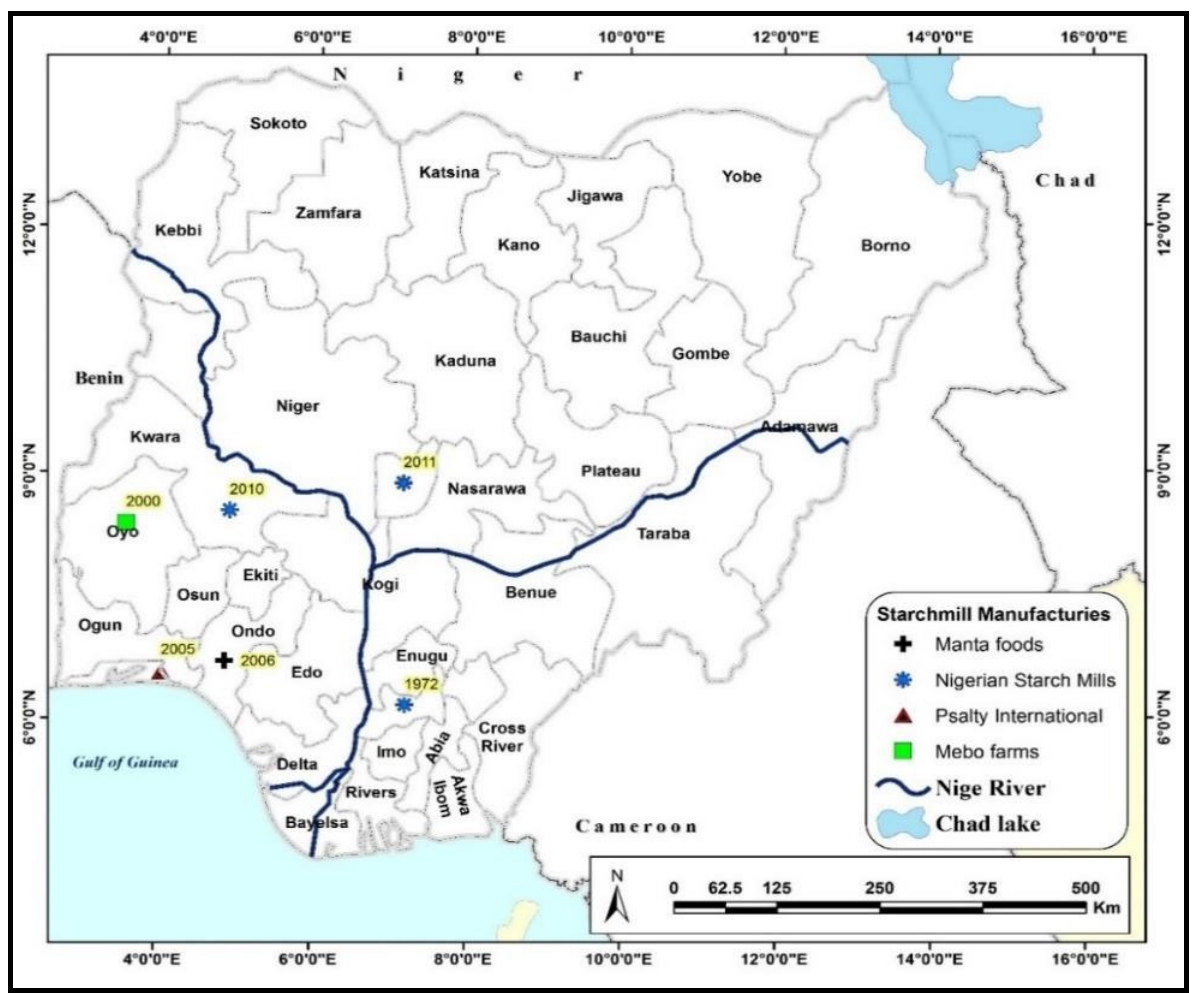

Figure 2. New starch operators established between 2010 and 2015. Source: Companies' official updated electronic websites.

Mebo Farm Limited is one of the largest starch producers in Nigeria, the operation relay on extracting starch from rice, maize, cassava, and wheat. It started at Lagos, and then established a new factory in Abuja in 2011. Two new 
states contributed in the last five years with starch manufacturing productions as Kwara and Abuja, while the production increased in Lagos by the same existent fabricators as they increased their manufacturing capacity.

\subsubsection{Manufacture of macaroni, noodles, couscous and Similar Farinaceous products}

The world food and financial crisis that occurred in 2008 affected the total consumption pattern due to the increase in prices. Macaroni and related products were produced in large amounts, and in different packing sizes. These products take the same time of operated such as prepared meals and dishes, as it experienced high demand between 2009 and 2015. However, the average of utilized manufacturing capacity of those production lines in Nigeria presents a slight increase since 2009; it gradually decreased between 2011 and 2013 before it rose again.

Table 5. The Manufacturing Capacity Utilization (Percent) of Macaroni, Noodles, Couscous, and Similar Farinaceous Products.

\begin{tabular}{|l|c|c|c|c|c|c|c|}
\hline \multicolumn{1}{|c|}{ Sub Sector/ Year } & $\mathbf{2 0 0 9}$ & $\mathbf{2 0 1 0}$ & $\mathbf{2 0 1 1}$ & $\mathbf{2 0 1 2}$ & $\mathbf{2 0 1 3}$ & $\mathbf{2 0 1 4}$ & $\mathbf{2 0 1 5}$ \\
\hline $\begin{array}{l}\text { Manufacture of Macaroni, } \\
\text { Noodles, Couscous and Similar } \\
\text { Farinaceous Products }\end{array}$ & 52 & 54 & 48 & 45.56 & 47.20 & 53.41 & 57.93 \\
\hline
\end{tabular}

Source: CBN, annual bulletin of 2010, 2011, 2013, and 2015.

For the noodles category, the World Instant Noodles Association (WINA) reports that Nigeria consumes 1,540 million tons annually, as the highest in Africa, since it has marked a gradual upsurge from 1,260 million servings in 2014 to 1,540 million servings in 2015. Its report came with the high record of schooled consumption of noodles in 2015 (World instant noodles association, 2015).

The financial statement reports of the grain milling company's shows between 2009 and 2016 a clear extended of their product lines to include macaroni and noodles on top of their wheat product lines. These include Flour Mills of Nigeria (FMN), Dangote Group, and Honeywell Flour Mills among others.

It has been noted that FMN owned $52.6 \%$ of the Niger mill limit (FMN, 2017). Since it has no manufactory in Cross River state, it acquired a high share of this factory to sustain its market in the eastern suitable state. In 2014, the Niger Mill saturated the Cross River market gap of semolina, noodles, and macaroni production in addition to other markets. Such products are not new in 
Nigerian food markets, but the local manufacturing units were starting to produce them in order to utilize the local food crops efficiently to dominate the market in order to increase their profits. The flour and starch mill producers are mainly the pasta and noodles producers, so the map has a little change as the development occurred between 2009 and 2015. Dangote Flour Mill (DFM) in 2014 established its new subsidiary as Dangote Pasta limited, and in 2017, it launched Dangote Noodles limited as both in Lagos, but not at Apapa estate (DFM, 2018). Dangote Pasta has a total capacity of 30,000 instant tons of pasta annually and has three noodles plants in Ikorodu, Kano, and Kano. Olam, established a direct business in the Nigerian market bought out the pasta producer. Regarding Amber Foods Co., which entered the pasta sector to take advantage of the growing market, as a branch of the BUA Group operated two wheat mills and a pasta manufacturing plant in Lagos. Recently it has a wheat and pasta manufacturing plant under construction in Port Harcourt at River state (BUA report, 2018, P.11). Honeywell Flour Mills introduced its pasta products in 2009, and in 2010 it started its noodles product lines. Flour Mills of Nigeria Plc operates one of the largest pasta and noodles plants in the country (Honeywell Four Mills-Nigeria, 2018).

\subsubsection{Processing and Preserving of Meat}

The trend of processing and preserving of meat had a slight increase between 2009 and 2011, as the total manufacturing capacity raised from $55.20 \%$ to $63.40 \%$. The production declined in 2012 for the favor of Poultry processing, and the average of manufacturing capacity utilization improved again as per high local population demand, especially in urban areas to jump from almost $55 \%$ in 2012 to be $72.30 \%$ in 2014 . This capacity continued its growth in 2015 to reach $80.5 \%$ and reflected the national supply in the shadow of newly implemented policies and environmental conditions. The market demand mirrors in the operation management in each year, since the local processors developed their capacity that slightly increased between 2013 and 2015. Nigeria still has the opportunity for such investments. The main key players in this manufacturing Sub-sector are four companies and the greatest share goes to UTC Company.

Table 6. Manufacturing Capacity Utilization of Meat and Poultry Products $(\%)$.

\begin{tabular}{|l|c|c|c|c|c|c|c|}
\hline \multicolumn{1}{|c|}{ Sub Sector/ Year } & $\mathbf{2 0 0 9}$ & $\mathbf{2 0 1 0}$ & $\mathbf{2 0 1 1}$ & $\mathbf{2 0 1 2}$ & $\mathbf{2 0 1 3}$ & $\mathbf{2 0 1 4}$ & $\mathbf{2 0 1 5}$ \\
\hline $\begin{array}{l}\text { Manufacture of Meat and } \\
\text { poultry products }\end{array}$ & 36.8 & 39.41 & 42.27 & 37.17 & 46.7 & 48.2 & 53.7 \\
\hline
\end{tabular}

Source: CBN, annual bulletin of 2010, 2011, 2013, and 2015. 
UTC leads the meat production in the country. It doubled its operations between 2011 and 2013 and got almost 42\% increase in its market supply (UTC Statement of financial position, 2014, p. 3). According to the conducted analysis of the financial reports of meat processor dominating manufactories, the company sustained this portion of capacity utilization and produced more between 2014 and 2015 to gain $30 \%$ of the national meat processing production. In 2013, UTC enlarged its investment in red meat units by $56 \%$, while it was $42 \%$ in 2012 in the same plant. UTC increased its investment capacity again between 2012 and 2013 by only $49 \%$, but this volume declined to reach $34 \%$ in 2014 and 15\% in 2015 (UTC annual reports, 2012, 2013, and 2014).

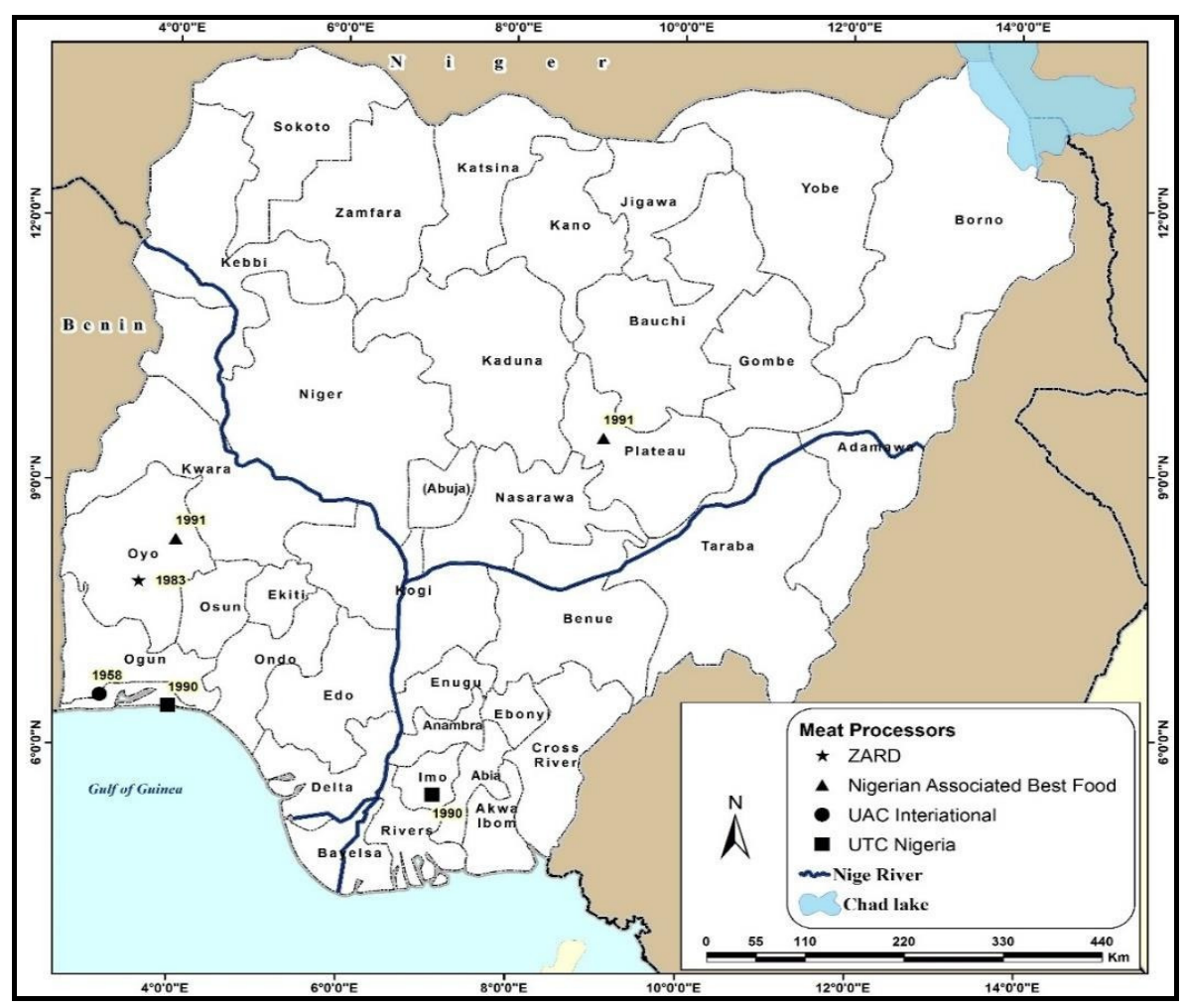

Figure 3. Poultry, cattle and goat processing and preserving meat established till 2016.

Source: Companies official data published in websites as new investments by state. 
The Company's business expansion initiative led to the acquisition of controlling equity in Livestock Feeds Plc., the foremost manufacturers of poultry feeds and $71.7 \%$ equity stake in Portland Paints and Products Nigeria Plc., makers of Sandtex paint. These acquisitions deepened the company play in the paints and feeds market (UAC-Nigeria annual report, 2015, p. 6). These expanded new investments let the company increased its process and preserved thepoultry and meat productions.

Nigerian Associated Best Foods Ltd, located at Oyo state developed its business at Plateau state as it increased its goat, poultry, and cattle farms between 2013 and 2015 to grow its Self-supply.

Zartech Company remained the leading player in frozen processed poultry as in 2012, accounting for a retail value sales share of $25 \%$. The company operates its own farm and stopped to rely on external suppliers, and leverages the concessions that the government offers domestic producers of poultry products, such as tax exemptions and import waivers. It avoided the tax of import ban on poultry meat, to increase its production and profit margins (USAID foreign Agriculture Service gain report, 2013, p. 5).

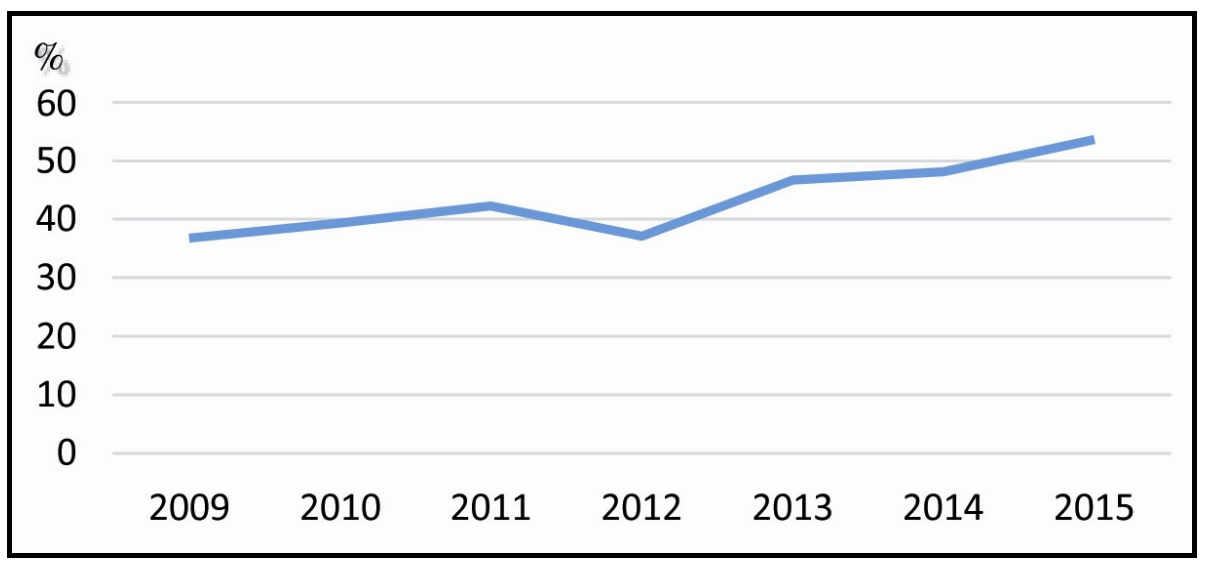

Figure 4. Trend of the Manufacture of Meat and poultry products Manufacturing Capacity Utilization between 2009 and 2015. Source: CBN, annual bulletin of 2010, 2011, 2013, and 2015.

The poultry production changed between 2010 and 2015. Since it started to decline sharplyto lose almost 1.5 million tons, the manufacturing capacity struggled for one year depending on the local farms before experiencing 
another sliding drop in 2012. The total country's poultryproduction witnessed a drop for the second time between 2013 and 2015 by almost 1.6 milliontons of preserving poultry productions (FAOSTAT, 2017) for the same reason of shortage in energy affordable prices.

\subsubsection{Processing and Preserving of Fish, Crustaceans and Molluscs}

Nigeria's fish and aquaculture production data has reflected that between 2010 and 2015 the total capture reached 5,788,474 tons, Table (7). Almost one billion Naira given as loans forfisheries to establish and expand their farms (CBN, 2018). Due to the conducted analysis by the researcher, it was clear that the national production testified growing gradually according to increasing the numbers of aqua-farms.

Table 7: The total of non-processed fish production between 2010 and 2015, value in Mt.

\begin{tabular}{|l|c|c|c|c|c|c|}
\hline Year & $\mathbf{2 0 1 0}$ & $\mathbf{2 0 1 1}$ & $\mathbf{2 0 1 2}$ & $\mathbf{2 0 1 3}$ & $\mathbf{2 0 1 4}$ & $\mathbf{2 0 1 5}$ \\
\hline $\begin{array}{l}\text { Total } \\
\text { captured }\end{array}$ & 817,900 & 859,614 & 937,255 & $1,023,636$ & $1,123,011$ & $1,027,058$ \\
\hline
\end{tabular}

Source: NBS, 2017.

Despite the highest production recorded in 2014, it was not the year of the maximum manufacturing operation capacity. The year 2013 witnessed the large volume of processed and preserved fish productions as pointed 59,871.0 Mt., as the rest of the products sold in the traditional forms as fresh, frozen, and salted products.

Table 8: Manufactured amount of fish and shrimp processed and preserved production between 2011 and 2015

\begin{tabular}{|c|l|c|c|c|c|c|}
\hline \multicolumn{2}{|c|}{ Sector/Year } & $\mathbf{2 0 1 1}$ & $\mathbf{2 0 1 2}$ & $\mathbf{2 0 1 3}$ & $\mathbf{2 0 1 4}$ & $\mathbf{2 0 1 5}$ \\
\hline \multirow{2}{*}{$\begin{array}{c}\text { Industrial } \\
\text { (Commercial } \\
\text { Trawlers) }\end{array}$} & Fish (Inshore) & 19,736 & 27,977 & 37,652 & 29,237 & 10,727 \\
\cline { 2 - 7 } & $\begin{array}{l}\text { Shrimp } \\
\text { (Inshore) }\end{array}$ & 13,749 & 17,654 & 22,219 & 20,715 & 4,737 \\
\cline { 2 - 7 } & Total processed & $\mathbf{3 3 , 4 8 5}$ & $\mathbf{4 5 , 6 3 1}$ & $\mathbf{5 9 , 8 7 1}$ & $\mathbf{4 9 , 9 5 2}$ & $\mathbf{1 5 , 4 6 4}$ \\
\hline \multicolumn{2}{|c|}{ Total Grand capture } & $\mathbf{8 5 9 , 6 1 4}$ & $\mathbf{9 3 7 , 2 5 5}$ & $\mathbf{1 , 0 2 3 , 6 3 6}$ & $\mathbf{1 , 1 2 3 , 0 1 1}$ & $\mathbf{1 . 0 2 7 , 0 5 8}$ \\
\hline
\end{tabular}

Source: NBS, 2017. 


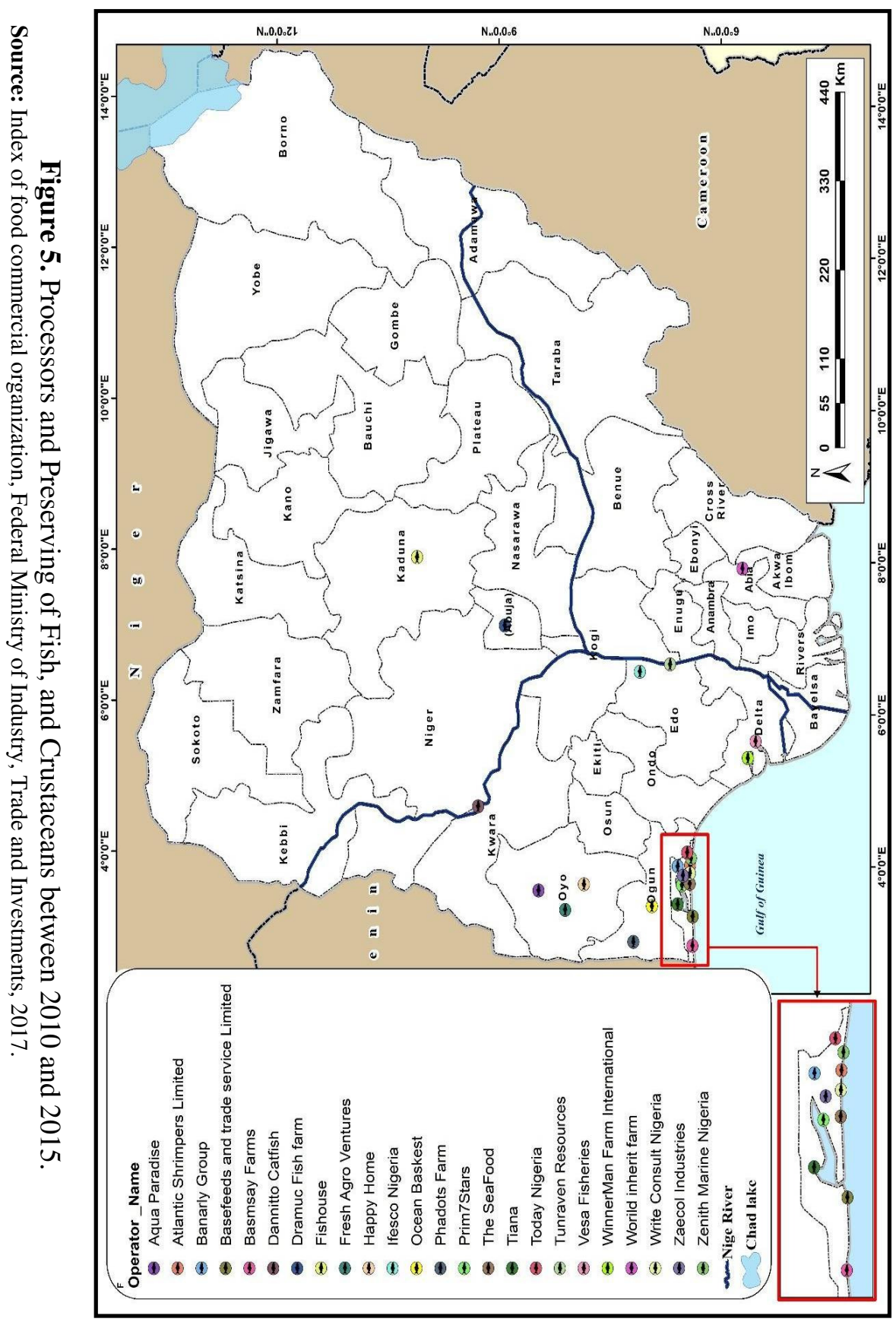

$-17-$ 
To reflect the manufacturing volume related to the total collected production, the analysisidentified the portion as follows; 39\%, 49\%, 59\%, $44.5 \%$, and $15 \%$ for the mentioned period respectively. The manufacturing has grown gradually with a margin of 10\% during 2011 and 2013 before it declined sharply from $59 \%$ to $15 \%$ in a couple of years. In fact, various farms were established since 2010, and that gives opportunities to increase local production from thelocal supply as 2013 total capture reflects. Due to the information given in Table (8) these declines in processing operations may be due to the farms that closed between 2013 and 2015 to withdraw from the manufacturing process. The CBN investigated about this decline and its assessment was detailed as this decline revised to marketing challenges and processing alternatives as enumerated by beneficiaries. The assessment recorded that production of fish recorded a number of challenges including; glut in the immediate environment, lacked/difficulty of access to markets beyond their immediate environments, rises in the cost of feeds and sensitivity of fish species to the environment. Those are responsible for the volatility in production and growth in income. Beneficiaries admitted failures to make good plans, and identifying marketing risks during the development of their business cases. (CBN, 2018). Between 2010 and 2013, almost 35 fish, seafood processing, and preservation manufacturers were established in the country, as most of them owned a private fish and shrimp farms to sustain and save their resources.

\subsubsection{Manufacturing of Dairy Products}

The dairy production development was beyond all expectations of the other Sub-sector categories in the country, as in light of the import bans as per governmental policies. The dairy manufacturers depended on the local production and achieved a high growth rate between 2010 and 2015.

Table 9. Manufacturing Capacity Utilization of Dairy Products (\%).

\begin{tabular}{|l|c|c|c|c|c|c|c|}
\hline \multicolumn{1}{|c|}{ Sub Sector/ Year } & $\mathbf{2 0 0 9}$ & $\mathbf{2 0 1 0}$ & $\mathbf{2 0 1 1}$ & $\mathbf{2 0 1 2}$ & $\mathbf{2 0 1 3}$ & $\mathbf{2 0 1 4}$ & $\mathbf{2 0 1 5}$ \\
\hline Dairy Products & 18.4 & 19.70 & 21.13 & $\mathbf{1 8 . 6}$ & 23.35 & 24.1 & 26.83 \\
\hline
\end{tabular}

Source: CBN, annual bulletin of 2010, 2011, 2013, and 2015.

It is an average of manufacturing capacity utilized depot in 2012 since it experienced slow movements until 2015. The annual growth rate did not exceed $1.7 \%$ to reflect the gradual increasing numbers of livestock farms that use new collection methods and technologies. That reduced the cost of production, hence the total production of all farms outputs did not achieve the local demand yet. The optimistic scenario of 
this $1.7 \%$ growth rate is the development occurred to the manufacturing utilized capacity pushed the other middle size investors to enter this category of the food operations. Furthermore, it gives the opportunity to the foreign investor to get some exceptions to continue importing more ingredients like powdered milk.

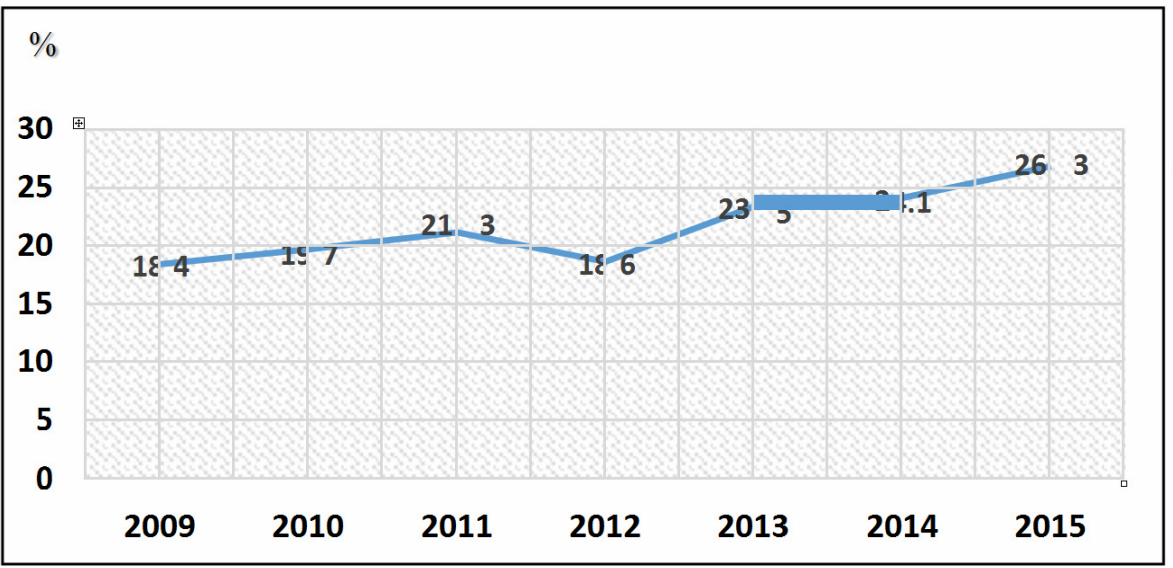

Figure 6. Trend of the Manufacturing Capacity Utilization of dairy between 2010 and 2015 .

Source: CBN, annual bulletin of 2010, 2011, 2013, and 2015.

No doubt that Nigeria still having a shortage in dairy production compared by the domestic market needs, especially with the recent population high growth rate and limited electricity supply to preserve such products. Due to the information provided by the CBN, shown in Table (9), the recorded information of the dairy manufacturing formal sector presents development since 2009 until 2011. This growth of the manufacturing capacity utilization experienced a growing trend until 2015, except for the drop of 2012.

\subsubsection{Processing and Preserving of Fruit and Vegetables}

Nigeria is not that subsistence food country anymore, however, its arable lands offer more forthe domestic increasing needs. The processing and preservation of fruits and vegetables witnessedgrowth during the mentioned period. However, the capacity of manufacturing utilized differentiated between 2010 and 2015 which dedicated declined in 2012 and 2013, manufacturers of the vegetable and fruits processing returned to increase their operations in the next two years. Nigeria produced a high amount of 
fruits and vegetables, and the trend of production recorded $23 \%$ as a growth rate, but this amount didn't go for processing in manufacturing format rather thanused as a fresh form.

Table 10. Manufacturing Capacity Utilization (Percent) of manufacturing of Fruit and Vegetables Products.

\begin{tabular}{|l|c|c|c|c|c|c|c|}
\hline \multicolumn{1}{|c|}{ Sub Sector/Year } & $\mathbf{2 0 0 9}$ & $\mathbf{2 0 1 0}$ & $\mathbf{2 0 1 1}$ & $\mathbf{2 0 1 2}$ & $\mathbf{2 0 1 3}$ & $\mathbf{2 0 1 4}$ & $\mathbf{2 0 1 5}$ \\
\hline $\begin{array}{l}\text { Fruit and Vegetables } \\
\text { Products }\end{array}$ & 24.31 & 30.54 & 34.21 & 20.08 & 23.81 & 34.68 & 38.01 \\
\hline
\end{tabular}

Source: CBN, annual bulletin of 2010, 2011, 2013, and 2015.

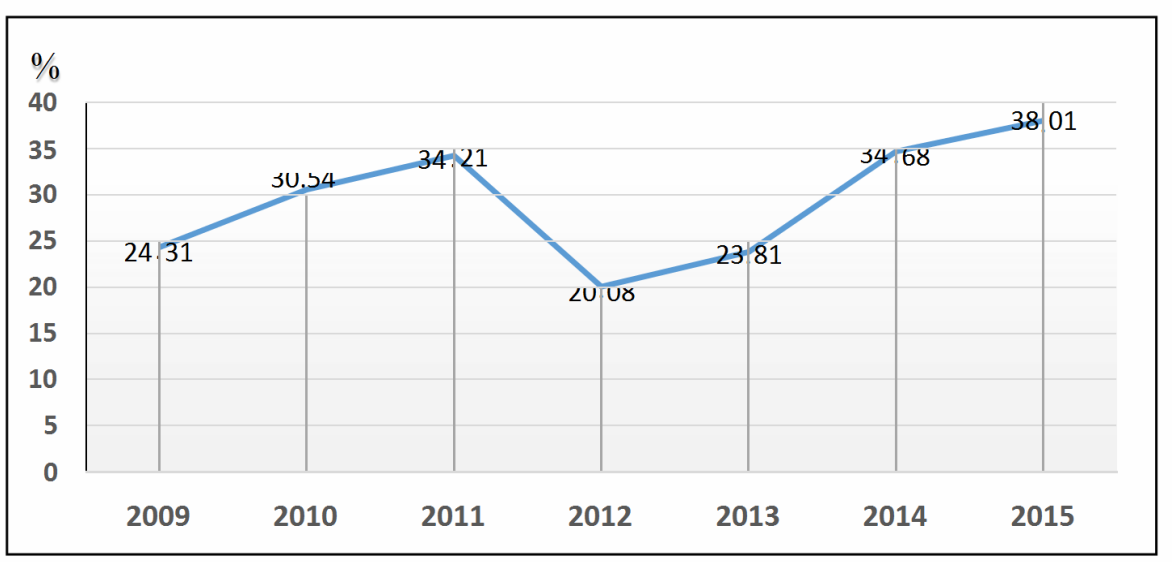

Figure 7. Trend of Manufacturing Capacity Utilization between 2009 and 2015.

Source: CBN, annual bulletin of 2010, 2011, 2013, and 2015.

Since people prefer to use this kind of food products in its fresh form, the fruits are many profitable products for the manufacturing firms as juice among other usages. These reflecting in beverages Sub-sector development as will discuss later. Different firms like the CBN and NBS indicated the affordable amount of vegetable and fruits in Nigeria can satisfy the domestic demand until 2020, (Nigeria agriculture sector performance review, 2018), (Annual collaborative survey of socioeconomic activities, 2009, p. 198).

The international agencies projected the shortage in that formula, especially in the local supplyside. According to the price of crops given by the $\mathrm{CBN}$; the researcher identifies this manufacturingmay need to develop on the industrial level, but it does not mean there is shortage in the local market 
needed for such products. The only exception for utilizing the manufacturing capacity for that segment of production increasing the urban consumption, or the manufacturers should find another rural demand. The food investors of flour and oil also entered the fruit processing and preservation in earlier 2010 to diversify their product profiles. For instance, Nigerian Associated Best Foods produced fruit juice, although it mainly specializes in meat processing. All soft drink operators also have production units of fruit processing.

\subsubsection{Manufacture of Vegetable and Animal Oils and Fats}

Although the total crop production of vegetable oils fluctuated in the mentioned period, the top production went to the palm oil crops for its international demand. Accordingly, the oil pressed volume improved during the period of five years topped by palm oil.

Oilseeds and products in Nigeria comprised of palm oil/palm kernel, soybean oil, and other oils. The first three oil types are contributing by $70 \%, 25 \%$, and $5 \%$ of the country's National Consumption Requirement (NCR), respectively. Others including peanut, cottonseed, coconut/copra, sesame seeds, rapeseeds, mustard seeds, castor seed, sunflower seed, linseed, etc. Production of oilseeds and products trending upwards in Nigeria, but domestic supply still lags behind growing demand which growing from both the poultry and the food processing industries. (USDA report, 2014, p. 2).

As reported in FAO several documents about Nigeria, as it ranks in producing and exporting palm oil, and its related products. The country still focuses its attention on this crop, and regarding the manufacturing of vegetable oil year 2010 witnessed the highest production during the period. That was returned to the manufacturing of palm oil, as well as its manufacturing capacity utilized in the same year to hit the national oil manufacturing capacity share to be $74.03 \%$.

However, two years witnessed high manufacturing outputs during this time as in 2012 and 2015. The total production recorded almost 1.39 and 1.37 million Mt. respectively, as the favor returned to the Kernel oil processing outputs. The portion of manufacturing capacity utilized in 2012 referred to $65.33 \%$, as the oil cottonseed recorded the highest volume during the mentionedperiod. 


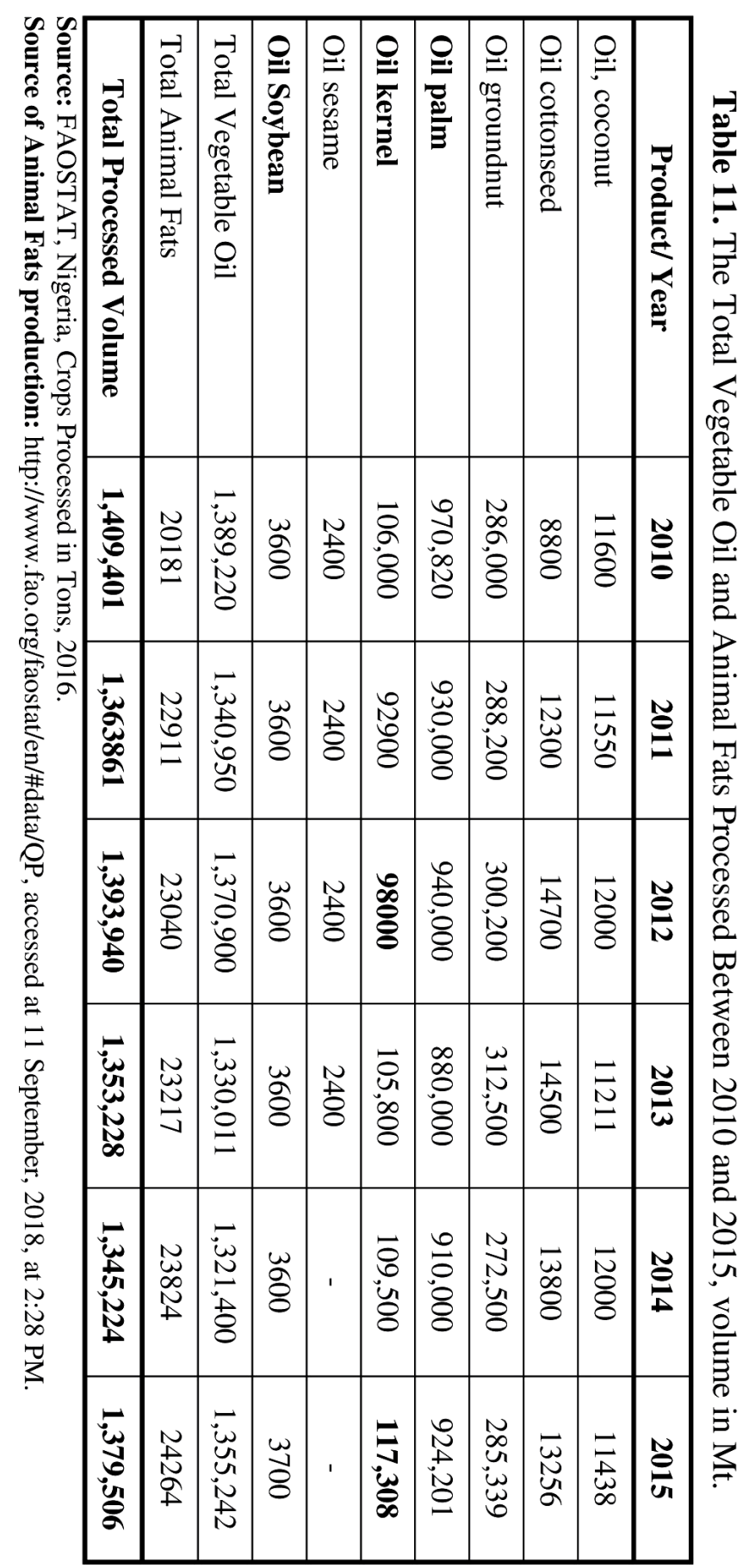

$-22$ 
Soybean meal also remains a vital and preferred source of protein in compound feed by the Nigerian poultry industry. A hike in soybean production and processing was stimulated by favorable grower prices and sustained high demand for soy meal by the poultry sector especially since the poultry import ban in 2006. The ban on poultry imports resulted in high demand for poultry feed in Nigeria. The growing demand for human consumption mainly in breakfast and baby foods, mixed with traditional foods such as "garri" (dough usually eaten with soup as a full meal) to boost protein content. The substitute for meat and fish in the form of soy cheese (tofu) is also an important demand driver.

The soybean oil demand as a preferred choice of vegetable oil has also shown significant growth during the period. Also, acreage increased because of the prevailing attractive prices. The Nigerian Local production estimated by 1.8 million tons has failed to pace with rising demand as the country's NCR reached 2.4 million tons. The 600,000-ton (about 25\%) difference met by imports. (USDA report, 2014, P.7)

Table 12. Oil and fats manufacturing capacity utilization (Percentage).

\begin{tabular}{|c|c|c|c|c|c|c|c|}
\hline Product/Year & $\mathbf{2 0 0 9}$ & $\mathbf{2 0 1 0}$ & $\mathbf{2 0 1 1}$ & $\mathbf{2 0 1 2}$ & $\mathbf{2 0 1 3}$ & $\mathbf{2 0 1 4}$ & $\mathbf{2 0 1 5}$ \\
\hline Oils and Fats & 60.88 & 74.03 & 68.52 & 65.33 & 79.01 & 84.16 & 86.42 \\
\hline
\end{tabular}

Source: Central Bank of Nigeria, production and consumption bulletin, 2017.

In response to the clear gap of domestic supply in the local market, and the perennial shortage of vegetable oil, the influx of low-quality grey imports into Nigeria. NASCON allied Industries in 2015, had commenced the production and sale of vegetable oil as high-grade refined product for domestic and industrial uses. Accordingly, the manufacturing utilization of 2015 increased to almost 86\%, since the mentioned year presented productivities booming of oil kernel and oil soybean. The palm oil pressed volume experienced a decline, but the vegetable oil pressing witnessed a new entrance of sesame oil with the same amount between 2010 and 2015. This was a very good opportunity to invest in this industrial Sub-sector.

Animal Fats also participated in this food-processing category, since the total manufacturing capacity utilization referred to both vegetable oil and animal fats. It has been noted from FAOSTAT given information, (FAOSTAT, 2016), that the volume of animal fats processed examined development gradually at the same period that matched with the trend of growing the manufactured capacity utilization portion between 2013 and 2015. 


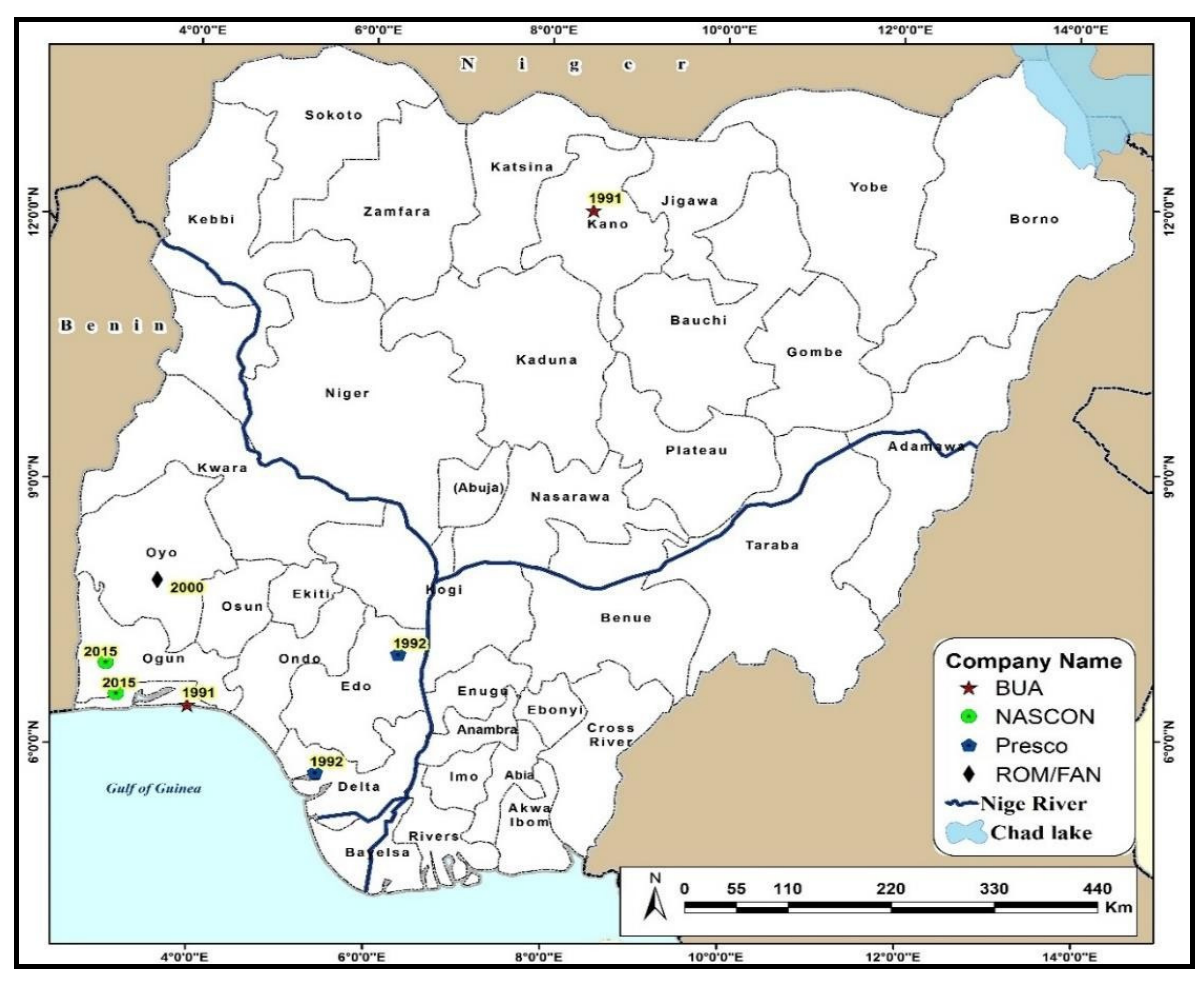

Figure 8. New manufactories and existing producers of vegetable and animal oils and facts, 2016.

Source: The locations of manufacturer available on their official companies' website.

Note: all manufacturers are listed in the Federal Ministry of Industry, Trade and Investment.

\subsubsection{Manufacturing of Bakery Products}

This category of food manufacturing considered as essential and basic food products, as the manufacturing of bakery products including snacks always find high demand as it considered as a basic need. That gives different producers in Nigeria a reason to produce more and increase utilizing their manufacturing capacity in a rapid way. Table (13) shows the capacity of manufacturing utilized was $62.65 \%$ in 2009 and increased gradually to reach $86.49 \%$ in 2015 witha growth rate of $1.5 \%$, reflecting the trended local demand on such products. Despite almost $24 \%$ increase in six years considered as little raise compared by the increased demand for such products, the local consumption hits the expectations as per recorded numbers of $\mathrm{CBN}$ report. 
Table 13. Bakery Product manufacturing capacity utilization (Percentage).

\begin{tabular}{|l|c|c|c|c|c|c|c|}
\hline Product /Year & $\mathbf{2 0 0 9}$ & $\mathbf{2 0 1 0}$ & $\mathbf{2 0 1 1}$ & $\mathbf{2 0 1 2}$ & $\mathbf{2 0 1 3}$ & $\mathbf{2 0 1 4}$ & $\mathbf{2 0 1 5}$ \\
\hline Bakery Product & 62.65 & 64.30 & 73.80 & 75.00 & 80.00 & 82.52 & 86.49 \\
\hline
\end{tabular}

Source: Central Bank of Nigeria, production and consumption bulletin, 2017.

The lowest growth rate was observed between 2012 and 2013, while in 2012, the government of Nigeria started to implement a policy as mandating cassava flour inclusion in wheat flour. The policy amends starting with a $10 \%$ of cassava flour to increase steadily to $40 \%$ by 2015 as mixedflour to use instead of wheat flour in bakeries. It was noted that Nigeria imported wheat from USAand milled it to produce flour locally, and according to that policies, the country planned for the wheat flour sourced $100 \%$ domestically.

The manufacturing of bakery products in Nigeria still fragmented between the formal and informal sector, since the consumption of bakeries inputs was exceeding the formal manufacturing supplies. Accordingly, the middle and small scales operators were the dominating players, despite the large Nigerian manufacturers like UTC, for example, increased its bakery operation capacities.

However, this manufacturing competed by the informal units, and the historical consumption information identified increasing in all its production patterns.

According to USAID reported in 2013, the expansion in the biscuit investments and bakeries manufacturing increasing by $40 \%$ about 550 million (950 gram) loaves of bread valued at approximately $\$ 700$ million were produced in Nigeria in 2012 (USAID Foreign Agriculture Service Gain report, 2013, p. 3)

To secure the basic food products, the government of Nigeria with the cooperation of foreignagencies and UNIDO started to fund the manufacturing of the bakery products. The funded project participants fully understanding the critical role played by the small and middle-size operators in this industry, and UNIDO funded SMEs working in this manufacturing since 2013 (Staple Crop Processing Zone Project Report, 2014, p. 13). According to the researcher analysis, this funding project is not reflected in the formal average of manufacturing capacity utilization, it influenced supplying the consumption market of such products between 2013 and 2015 . 


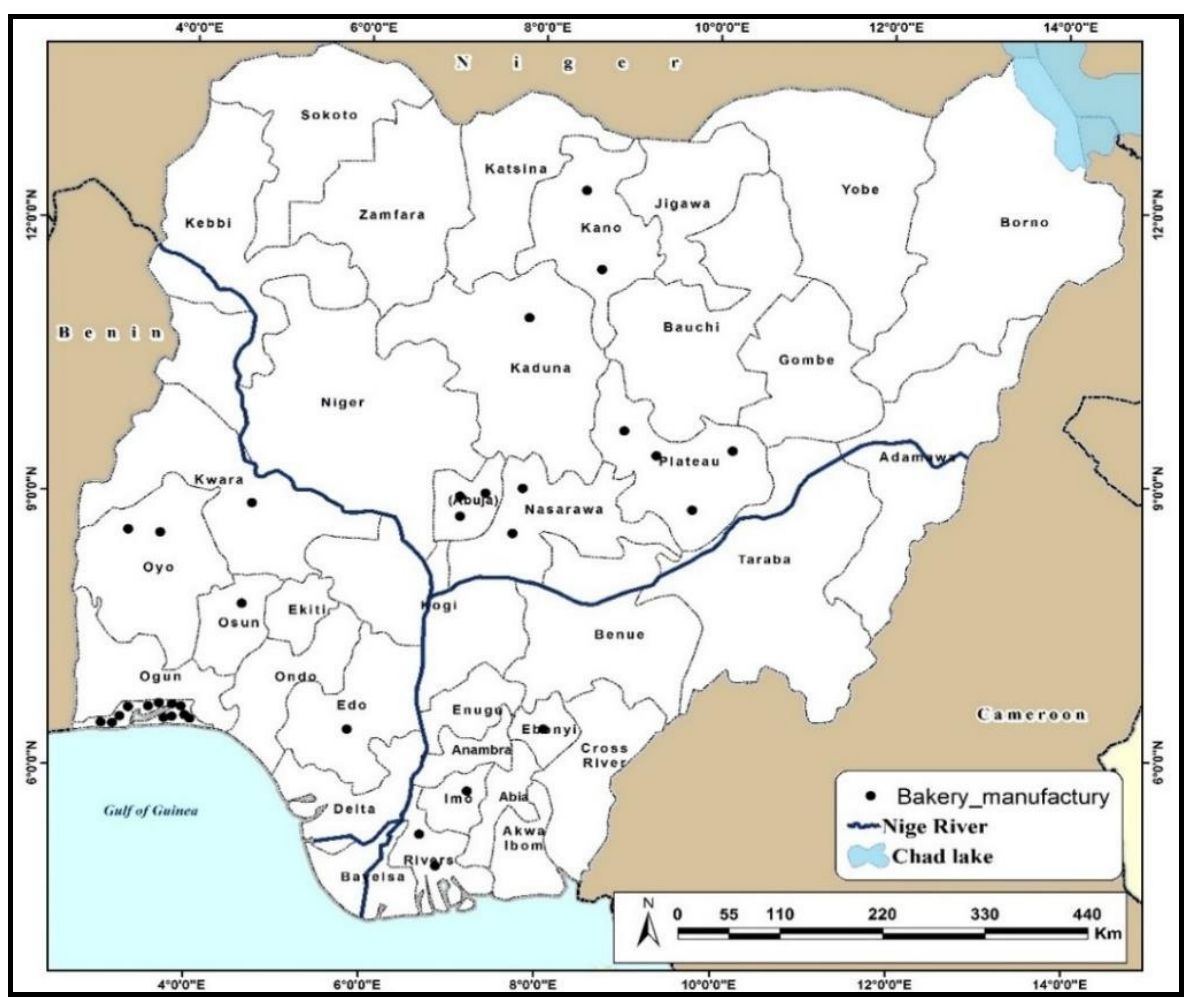

Figure 9. Bakeries manufacturing operation units between 2010 and 2015.

Source: https://www.businesslist.com.ng/companies/bread, accessed at: 20 September, 2018, 8:30 AM.

\subsubsection{Manufacturing of Refining Sugar}

The manufacture of sugar refinery expanded by large investments between 2009 and 2015, as only five investors controlled the manufacturing between the 1960s and 2008. The situation changed in 2010 as the structure of sugar manufacturing seeking more productivity. Those five operators compressed into only three firms with a mature share of foreign investors' participation.

Lafiagi Sugar Company Limited established in the 1970s with 60,000 tons per year increased the capacity to reach 100,000 tons a year. In 2008, BUA acquired Lafiagi Sugar Company Limited to produce 460,000 tons a year. (BUA, 2017). South African investors started to expand in the sugar refining business when Tiger Company shared Dangote Sugar to develop its sugar business in 2011 as the main business partner. This appeared in the manufacturing utilized capacity in 2012 as the DSR considers as the largest sugar producer in the country. 


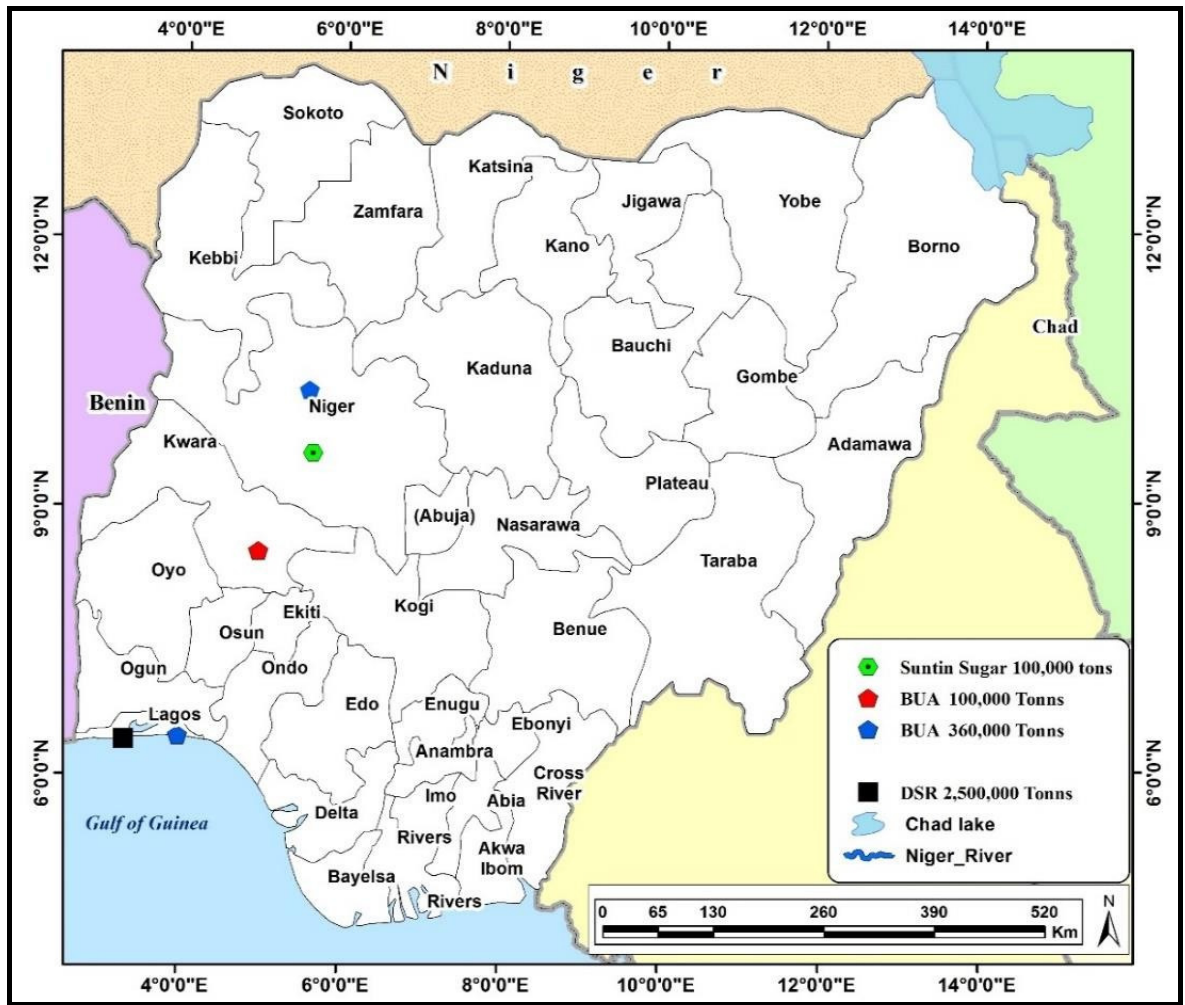

Figure 10. Sugar Refining capacity between 2010 and 2015 due to existing operators.

Source: National Sugar Development Council, and locations and volume of production collected from companies' official websites, 2017.

Dangote Sugar Refinery (DSR) acquired 95\% of the Savannah Sugar Company Limited in 2011 to increase its capacity since it produced in 2012 almost 2.5 million Mt. instead of 1.5 million Mt. a year. (Dangote group annual report, 2018, p. 12). In that way, DSR controlled $80 \%$ of the Nigerian market, and $90 \%$ of the local manufacturing between 2010 and 2015. The company reduced the cost of the sugarcane-imported volume since it also acquired the local farms of Savannah Sugar Company Limited. This came with attendance of the bans on imported crops, as most of sugarcane imported by DSR was from Brazil. In 2013, DSR started to expand its business as a Self-supply by cultivating new farms of sugarcane.

Nigerian Sugar Company (Bacita) in 2011, started to suffer after a new private owner entered the Nigerian market, and ended its activities. While 
Sunti Sugar Company, Jebba, developed it's manufacturing by producing $100,000 \mathrm{Mt}$. instead of 60,000 Mt. annually, it harvested three thousand hectares of sugarcane out of 17,000 hectares (Pulse report, 2018, pp. 3-9).

Table 14. The Manufacture of Sugar manufacturing capacity utilization (Percentage).

\begin{tabular}{|c|c|c|c|c|c|c|c|}
\hline Product/Year & $\mathbf{2 0 0 9}$ & $\mathbf{2 0 1 0}$ & $\mathbf{2 0 1 1}$ & $\mathbf{2 0 1 2}$ & $\mathbf{2 0 1 3}$ & $\mathbf{2 0 1 4}$ & $\mathbf{2 0 1 5}$ \\
\hline Manufacture of Sugar & 60.25 & 73.77 & 79.34 & $\mathbf{8 2 . 7 1}$ & 79.02 & 75.44 & $\mathbf{8 5}$ \\
\hline
\end{tabular}

Source: Central Bank of Nigeria, production and consumption bulletin, 2017.

The previous status of sugar refining dominating companies clarify the new structure of this manufacture in the local industrial field. Since 2010, the market testified increased in local production, as the manufacturing capacity utilized from 2009 . It recorded $60.25 \%$ to reach an average of almost $85 \%$ in 2015 , as the highest portion during this period. Another reason for this development was what privatization adopted, as one of the great refineries had purchased the Simigovernmental sugar manufacture. This step rewarding the manufacturing by self-sourced raw crop, and develop the local population income at the same time. The manufacturing of sugar refining in Nigeria is dominated recently by four companies as mentioned before, and this manufacturing capacity reflects only the formal sector because the informal sector cannot participate or runs such a refinery.

\subsubsection{Manufacturing of cocoa, chocolate and sugar confectioneries}

Cadbury Nigeria is the largest cocoa processor in the country since the 1950 s as mentioned before. In 2013, it led others in chocolate manufacturing, as it occupied almost $26 \%$ of the market share in the same year (KPMG, 2014). Nestle Nigeria is another company known for brands of chocolates that competes with Cadbury in the market place. Efforts are also being made by newly established, 2012, local chocolate manufacturing companies like Multi-Trex to launch the massive production of chocolate bars. Multi-Trex Integrated Foods Plc., engaged in the processing of cocoa beans, the exportation of industrial cocoa products, and manufacture plus marketing of cocoa-based consumer products. Its products include cocoa liquor, cocoa cake, cocoa butter, cocoa powder, and chocolate powder. The company exports its products primarily to Europe. TULIP cocoa processing limited is a company established in 2006, to prepare and process cocoa for both domestic and international consumption (Nigerian export promotion council annual report, 2016, p. 14) 


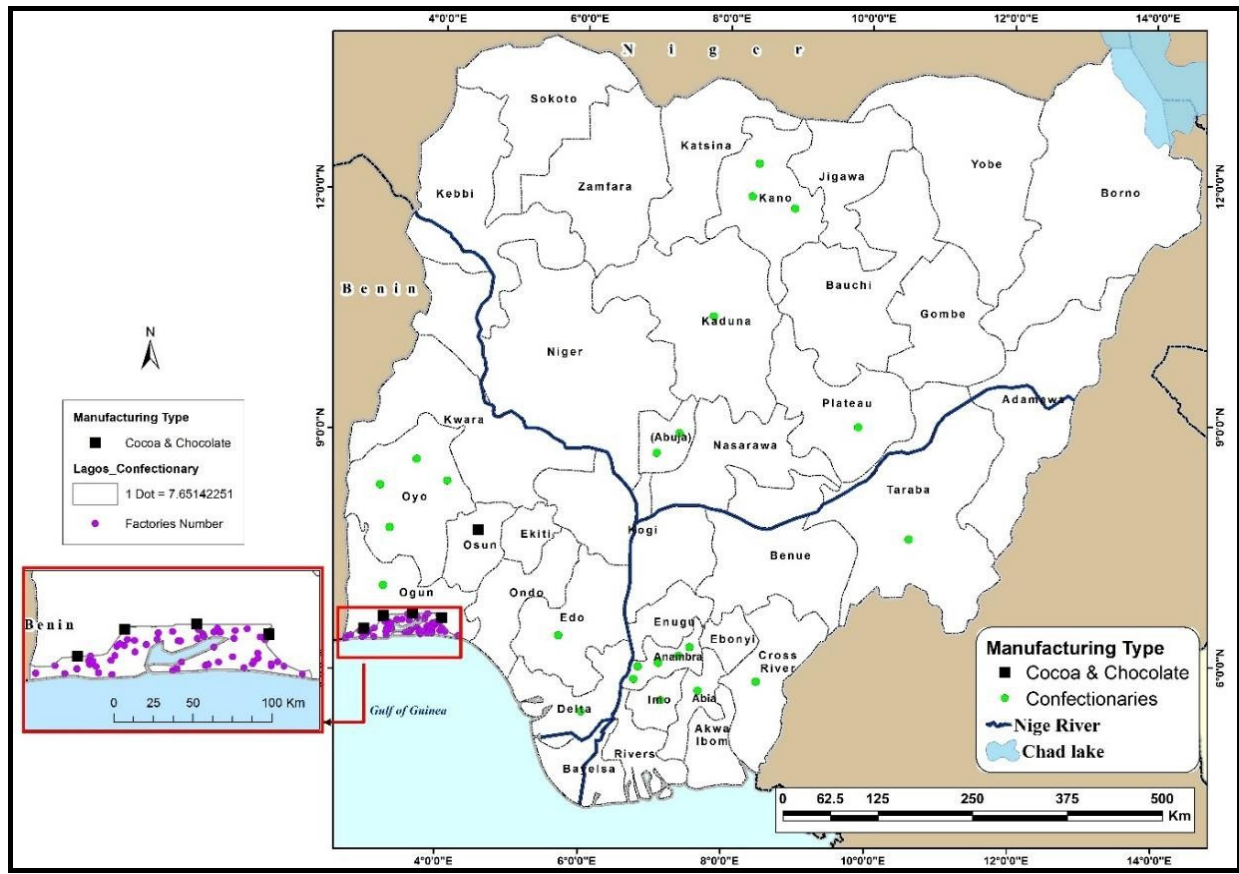

Figure 11. Cocoa, chocolate and confectionery processors in Nigeria between 2010 and 2015.

Source: Cocoa Association of Nigeria, available at: https://www.cancocoa.org/, accessed at 17 October 2017 at 3:24 PM.

This kind of manufacturing has two parts, as the first one is cocoa processing for food purposes controlling $30 \%$ of the total domestic cocoa production, and the second part is preparing cocoa beans for exporting purposes. The growth is shown in table (15) returned to sugar confectionery manufacturing utilized capacity.

Table 15. The portion of cocoa, chocolate and sugar confectionery manufacturing capacity utilization.

\begin{tabular}{|c|c|c|c|c|c|c|c|}
\hline Product /Year & $\mathbf{2 0 0 9}$ & $\mathbf{2 0 1 0}$ & $\mathbf{2 0 1 1}$ & $\mathbf{2 0 1 2}$ & $\mathbf{2 0 1 3}$ & $\mathbf{2 0 1 4}$ & $\mathbf{2 0 1 5}$ \\
\hline $\begin{array}{l}\text { Cocoa, chocolate, and } \\
\text { sugar confectionery }\end{array}$ & 24 & 72 & 69 & 72 & 74 & 79 & 83 \\
\hline
\end{tabular}

Source: Central Bank of Nigeria, production and consumption bulletin, 2017.

The formal sector recorded 60 companies managing factories in Nigeria, as distributed shownin Figure (11). In 2009, the capacity utilized was only $24 \%$ due to different challenges as import bans, food crisis, financial crisis, 
and currency inflation. Two years later, Nigeria witnessed sustained growth except in 2011, as a little declined than the total average which affected by the total sugar production to supply in the same year. (Euro-monitoring international, 2018) published market research focused on sugar confectionery in Nigeria to report that in 2015, about 36 middle- sized investments of confectionery manufactories run their operations at Lagos State.

\subsubsection{Manufacturing of prepared meals and dishes (Miscellaneous Food Preparation)}

The business of restaurants and hospitality is highly dependent on such manufacturing production as the poultry dish prepared at the casual markets in the country as public places and streets. The competition started in 2010 from the informal sector, since the high production needs to own power supplies to reduce the total cost that isn't sufficient by the local middle-size factories.

Those who facing different challenges after the financial crisis of 2008.

Table 16. The prepared meals and dishes manufacturing capacity utilization (Percentage)

\begin{tabular}{|l|c|c|c|c|c|c|}
\hline \multicolumn{1}{|c|}{ Product /Year } & $\mathbf{2 0 1 0}$ & $\mathbf{2 0 1 1}$ & $\mathbf{2 0 1 2}$ & $\mathbf{2 0 1 3}$ & $\mathbf{2 0 1 4}$ & $\mathbf{2 0 1 5}$ \\
\hline $\begin{array}{l}\text { Prepared meals and } \\
\text { dishes }\end{array}$ & 51.44 & 48.20 & 63.10 & 72.30 & 75.90 & 69.54 \\
\hline
\end{tabular}

Source: Central Bank of Nigeria, production and consumption bulletin, 2017.

It was observed from data given in Table (16) that only $51.44 \%$ of the manufacturing capacityused and in 2011 it reached $48.2 \%$. This may return to a wide range of restaurants and hotels provided fresh food instead of frozen to attract more customers to increase their cash. A year after the capacity increased to $63.1 \%$ as per the high demand of the supermarket chains. The process returned to the upgraded records in 2012, as the previous year indicated the high need for such products. Prepared meals and dishes increased again due to the high prices the country testified as the volume of immigrants increased the food prices especially in the urban areas rather than ruralmarkets.

Those operations are largely depending on the ready process as types of machineries on hand, and good preservation on another hand. The decline presented in the portion of 2015, mirrored the inflation high rate and its impact as reacted to the purchasing low power. This manufacturing category 
includes fresh and prepared dishes with processing value-added that increased the total prices of the products.

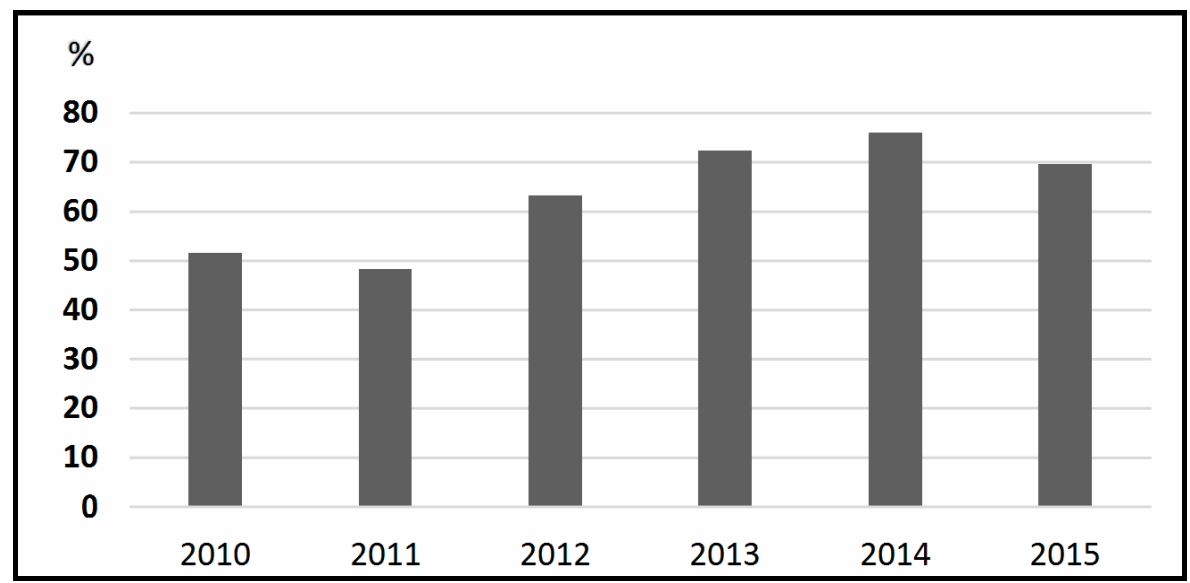

Figure 12. Trend of Prepared Meals and Dishes Manufacturing Capacity Utilized percentage between 2010 and 2015.

\subsubsection{Manufacturing of the other food products \\ 1.2.11.1 Salt Industry}

It observed based on given data that in 2015, five salt refining operators existed instead of those three were between the 1970s and 2009. The best table refining salt produced by NASCON which has three factories as mentioned in chapter one, while the others had less investments in this Sub-sector category. According to the financial analysis at the end of 2015, the NASCON production profits declined by almost $25 \%$ because of the harsh operating environment, since it increased by 30\% in 2013 and 27\% in 2011. In 2013, Dangote Salt bought the National Salt Company, and merged it under name of NASCON, and in 2014, the business expanded its production lines to further increase profitability in line with the long-term growth objectives.

The changes that occurred in this manufacturing between 2010 and 2015, can be summarized in two main processes. First, three middle-sized companies had invested in refining editable salt products among other salt products. The optimistic scenario is those manufacturers established their operation units using technologies of machines to reduce both labor costs, and time of operations according to the high demand for such an essential product. While the development increased the value-added of three states like Lagos, Rivers, and Ogun states, and of course the taxes to the administration states. The rest of the coastal states still suffering from such integration. 


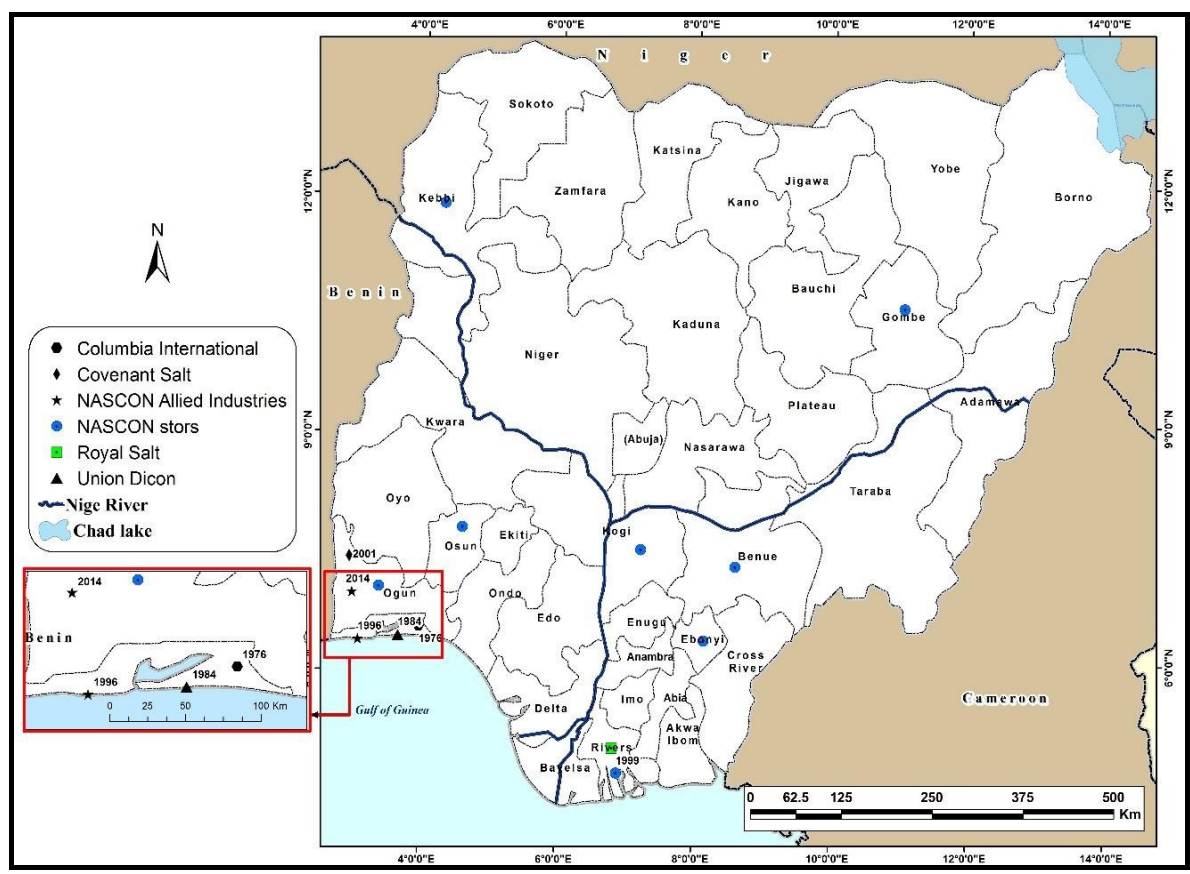

Figure 13. The Salt refineries and stores between 2010 and 2015. Source: The official websites of the companies dominating the local market.

The second point is that Dangote group bought the National Salt Company to increase its profit of salt operations since it was located also at Lagos state. Noted that this company was owned by the public sector. Finally, salt manufacturing from 1974 until 2015 was located in the same states, and any development of competition in this Sub-sector is attracted by the same states. At the same time, the stores were finally distributed in states to supply surrounding markets.

\subsubsection{Beverages manufacturing development 1.2.11.2.1 Breweries}

The breweries investments since the 1960s were limited to foreign investors, and in the 1970s, a large share of indigenous investors started to invest in beer. It has seen, based on Table (17), that the manufacturing capacity increased gradually in this beverage category between 2010 and 2015 to witness a drop in only one year as recorded in 2014. The growth between 2011 and 2012 was almost 20\%. It seems that the new imported technology pushing the advancements of production volume to reach this level of manufacturing utilizing capacity. 
Table 17. Beer \& Stout Manufacturing Capacity Utilization (Percent).

\begin{tabular}{|c|c|c|c|c|c|c|}
\hline Sub Sector/Year & $\mathbf{2 0 1 0}$ & $\mathbf{2 0 1 1}$ & $\mathbf{2 0 1 2}$ & $\mathbf{2 0 1 3}$ & $\mathbf{2 0 1 4}$ & $\mathbf{2 0 1 5}$ \\
\hline Beer \& Stout & 56.81 & 61.83 & 81.31 & 92.43 & 75.39 & 96.48 \\
\hline
\end{tabular}

Source: CBN, Statistical Bulletin Section C Final, 2015.

Nigerian Breweries led this manufactory Sub-category, as in 2011 it increased the capacity toproduce three more products, and started to produce some of its brands in cans. The company documented that in 2011 since it bought both Sona Breweries and Life Breweries Company. Threeyears after, the company acquired another firm as Consolidated Breweries in 2014 (Nigerian Breweries Plc., 2018).

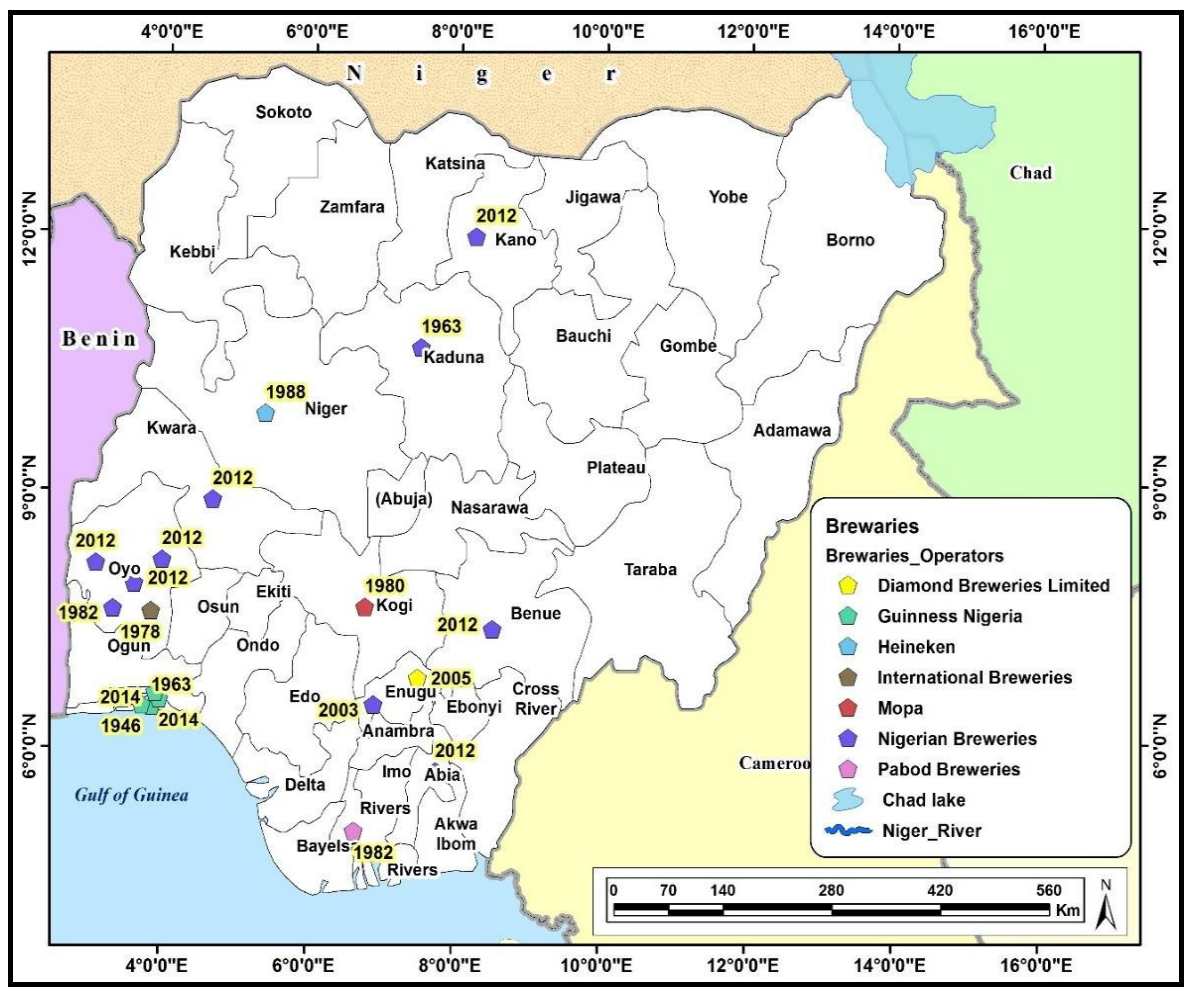

Figure 14. Distribution of Breweries Manufacturers in Nigeria between 2010 and 2015.

Source: Official documents available on the companies' websites, 2017.

As observed this acquisition aimed to expand its operation at a new location, and the consequences reflected in its speculated productions between 2010 and 2015 since it produced new 59 products. According to its 
manufacturing leadership, and its industrial domination the company played a vital role in the national capacity utilization in 2012 as almost $20 \%$ increase. In 2015 more than $25 \%$ increment of the manufacturing capacity utilization. This series of acquisitions by Nigerian Breweries changed the breweries map of Nigeria, and it almost dominated the breweries manufacturing in the country. The new form of Nigerian Breweries enables it to control the holistic Nigerian market, and utilize all available crop productions to produce more.

\subsection{Soft Drinks}

It has been observed, as per CBN data given in 2015, that between 2010 and the end of 2015, the soft drinks units developed with a steady growth rate. It belonged to the pushing trend of consuming healthy food, and the common consumer preferred it more than breweries or carbonic drinks (CBN, 2015).

Table 18. Soft Drinks Manufacturing Capacity Utilization (Percent).

\begin{tabular}{|l|c|c|c|c|c|c|}
\hline \multicolumn{1}{|c|}{ Sub Sector/ Year } & $\mathbf{2 0 1 0}$ & $\mathbf{2 0 1 1}$ & $\mathbf{2 0 1 2}$ & $\mathbf{2 0 1 3}$ & $\mathbf{2 0 1 4}$ & $\mathbf{2 0 1 5}$ \\
\hline Soft Drinks & 40.73 & 53.60 & 73.22 & 77.64 & 81.33 & 83.01 \\
\hline
\end{tabular}

Source: CBN, Statistical Bulletin Section C Final, 2015.

In 2012, Coca Cola Company bought Chi Limited, as it was the largest juice and dairy producer in the country. As mentioned before, Coca Cola agreed with Nigerian bottling company to bottle and distribute its carbon and soda drinks. It seems that this acquisition was planned, especially after Coca Cola gained $40 \%$ of Chi investment shares in 2009. Since then Coca Cola holds the largest share in the beverages manufacturing filed that may clarify the jump of the total portion between 2011 and 2012 to reflect almost 20\% growth of the utilized capacity before its upsurge by about $4.4 \%$ during 2013 . While the difference was almost 13\% between 2010 and 2011, the merging reflects that the site vertical integration as both locates at Lagos State.

Between 2013 and 2015, almost 15 companies entered the soft drinks manufacturing sector asmiddle-sized investors. Lagos state gained two-thirds of this volume as 10 factories were established there (Statistical department report, 2017). Figure (15) shows the new distribution of all soft drinks' factories run their operations between 2010 and 2015. It has been noted that Lagosstate controls the three greatest food-processing activities that pushing up the total food manufacturing outputs that participated in the GDP of 2015. It leaves the other shares to extend in the other commercial sited in different states such as in Kano and Kaduna states among others. Atthe same period, different manufacturing merged with others, and this in some cases 
leads to increase the manufacturing operations due to best management approach. However, this integration reflects the best scenarios, it mirrors losses in other cases, and slow performance and declining of utilized the full manufacturing capacity in the other cases.

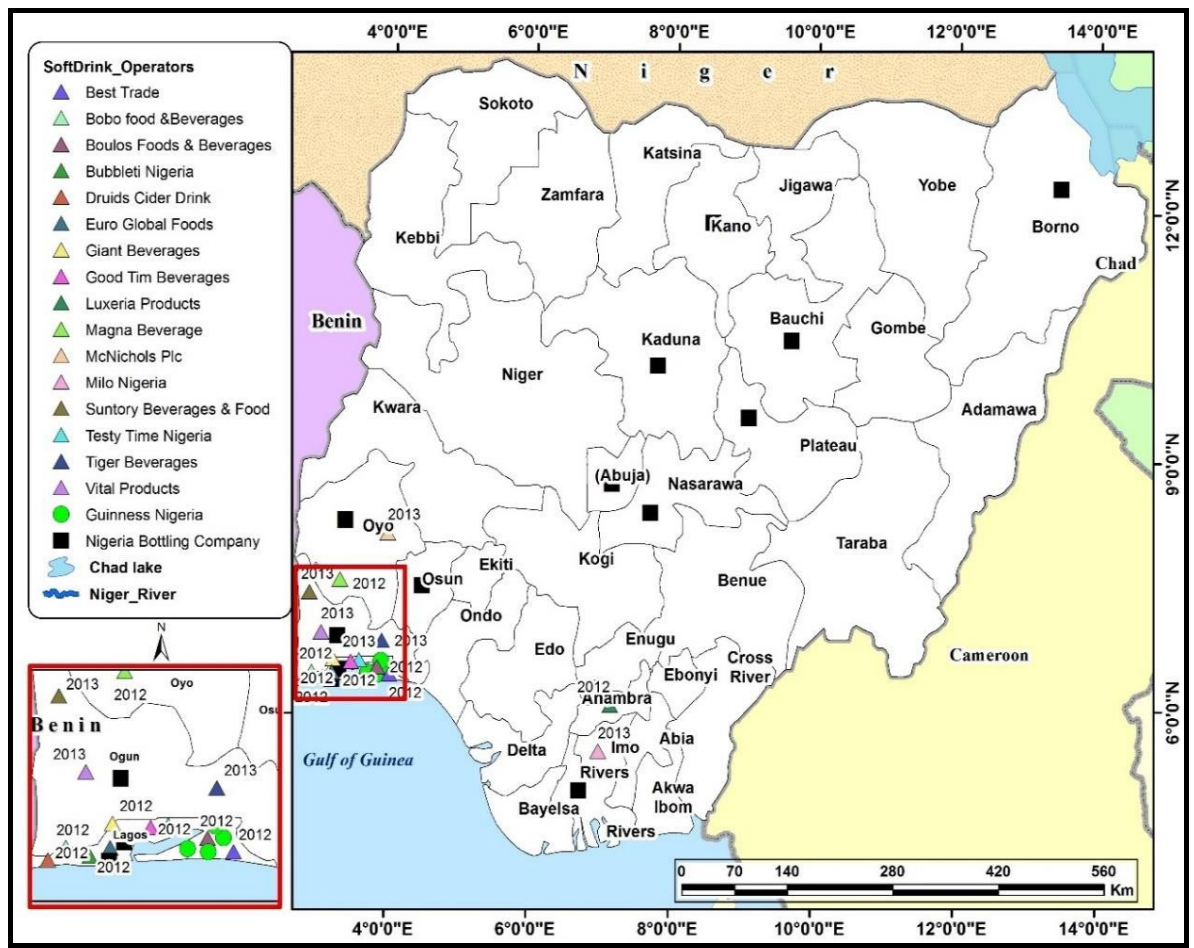

Figure 15. Distribution of Soft Drink Factories between 2010 and 2015. Source: Federal Ministry of Industry, Trade and Investment, Statistical department report 2017.

\subsection{Food and Beverage Sub-sector Analysis \\ 1.3.1 Rural-Urban Food Industrial Weights}

The food industrial chain often starts from the rural areas as mentioned as initial phase making rural areas control this phase, but sometimes this chain starts in the urban areas if the raw materialwere imported from abroad with attendance of an efficient logistic method such as seaport or another transportation hub. A clear example is given in Nestle milk product line which imported the milk powder from Poland, Netherlands, and at the same time it exported the cocoa products to Europe. The other example was in DSR, as it imported the sugarcane from Brazil. That was the reason for localized their food manufactories at Lagos to be nearby the Lagos-port, and located inextremely urban areas. 
Post-harvesting phase increases the value-added of the raw materials influencing positively the farmers' income level, and reducing the wastes for manufacturers. According to the Nigerian industrial index, most of the middle size investments in vegetable oil presses and grain millers are widely spreading in small towns. Since 2013 and until 2015, the average of almost $30 \%$ of the workers shifted from farming to food processing activities to start their own business in towns supported by the Bank of Industry "BOI". The CNB report confirmed this as almost 220 Billion Naira given as loans to support household small scale business loans including food preparing projects at the same period (CNB, 2017). It has been observed from the loans by type categories that the shift of working in related economic activities, from agriculture to agro-industrial business, often comes as a result of the high inflation rate. The middle and small processors profited from the operation of the pro-post harvesting tasks more than agriculture activity itself.

These shifting efforts came after a long experience of the unsupported governmental reactionsregarding the profitable prices of the crops between raw producers and merchants. The seed merchants sell seeds in high prices that reduce the margin profit of the final crops' prices. (Bolarin Titus Omonona, 2006, P.446). Different studies provide a little gap in seed prices and crop production prices (Chinedum Nwajiuba, 2013, P.5) mentioned in his study that one of the main challenges of food security in Nigeria is the low difference between food crop seed prices and cropproduction prices. (P. Kormawa, E. Okorji, R. Okechukwu, 2015, P.244) also mentioned the same problem in different periods.

According to the F \& B manufacturing distribution in the country, it seems that the merchant model by James Vance, that was developed in 1970 to explain the progress of the market and merchant relationship between developed and developing countries have been repeated in Nigeria. This model targeted the excavation of mineral trade. The same merchant model was observed by the recent spatial analysis, but it detected in the food manufacturing operations pattern through the country. It started by Lagos state, without any rural areas involved, to expand gradually through the country. As observed from the food industrial manufacturing locations that urban areas have afaster manufacturing operational chain than rural areas.

The first core was the establishment of industrial estates in Lagos by British colonization, and then completed by the local Nigerian government. The affordable facilities pushed increasing numbers of the generated factories. It has been noticed that the first national industrialization strategic plan, which 
settled after independency, reflected positively in the industrial development in Nigeria. The government built more industrial estates and Industrial layouts to implement the best processing performance to succeed in the mentioned plan. Those estates and especial areas offered infrastructure facilities to attract various industrial investments are clearly present the development, such as the case of the sugar refining performance at Ikeja, and Apapa industrial estates in Lagos. It has been realized that two states have monopolized sugar manufacturing out of thirty-six utilizing their industrial estates within the urban areas instead of rural areas. Cocoa processors also concentrate their operations in the three industrial estates established in the urban areas, nearby ports to be easy to export their products as per importer requirements. Similarly, the processor of palm oil and pasta producers, while dairy manufacturing in Ikeja estate at Lagos was operated as it gets the imported raw materials through the port of Lagos. Another implemented example has been recognized in the sugarcane crop cultivated far by these estates, and transported using railways, except those belonging to BUA.

The food industrial internal relationship between rural and urban areas never enclosed to In- site processing in rural areas and complete industrial operations in urban areas. It extends to reverse in marketing the final products in both as well. Although leakages in the infrastructure were in small cities, most of these cities have huge numbers of the second phase operators of the food industrial operational chain. The shortage of the different infrastructure layers in most of the rural areas gives superiorities to the food crop collectors to play a critical role in Rural-Urban operational relationships. The role of collectors as the middle chain augments the processing operation in the urban chain more than in rural areas. It has been marked that the socioeconomic attitude stands behind the adverse immigration, which is not limited to crop trading or agro- industrial trend. It including the new investments in different small manufacturing units. Cities control about $70 \%$ of the total food manufacturing operations and leave the rest for rural areas as the initial phase including the preparation phase. This mentioned portion includes all foreign investments that are preferred to locate at the industrial estates seeking investment's cost- effectiveness. What makes it worse is the food speculated prices in early 2008, (CBN-statistical report, 2016, p. 3) and the economic crisis between 2010 and 2013.

\subsubsection{Food and beverages manufacturing Geo-evaluation and weight analysis 1.3.2.1 Food industries Geo-evaluation analysis}

Due to Nigeria Investment Promotion Commission (NIPC-list of food, beverages and Tobacco companies, 2016, pp. 210-345) given information 
over the period between 2010 and 2015, the total manufactories that process F \& B in Nigeria reached 1,114 out of 10,461 factories. In details; this amount included both Food processing factories as 1042, and the Beverages processors as 72 to present almost $93.5 \%$, and $6.5 \%$ respectively in 2015 . Presents cumulatively about $20.4 \%$ of the total active manufacturing firms in the country to participate with $45.55 \%$ of the total productive outputs from the manufacturing sector.

The numbers of large-size investments are not an accurate indicator to evaluate the real impact of food industries on the macro level. It must evaluate the distribution of food industries through the country regardless of its Sub-class. The manufacturing volume is not an accurate indicator to evaluate the real effectiveness of food industries, because it does not reflect the number of the labor force occupied by this industry. At the same time, the percentage of food manufacturing numbers compared by the total manufactories also mirrored the quantitative methods, but not the qualitative value. In this respect, scientists reached out another industrial indicator as Industrial Quantum Coefficient (IQC). In Nigeria this analysis will be implemented to the recently available data (2015) at the micro-level, state level, to access the geographical, spatial, coefficient for the industry involved in this study. The industrial specialization analysis will not implement in this study because of different reasons included the various manufacturing types through the country. The IQC implemented here as an indicator to assess the valued impact of the food manufacturing effectiveness distribution to clarify the industrial weight, and the portion of F \& B manufacturing out of the total manufacturing sector. The Industrial Quantum Coefficient (IQC) (Soltan Foly Hassan, 1997, pp. 180-182 in Arabic). The researcher used it as given formula as below:

\section{Food and Beverages $\mathrm{IQC}=\mathrm{Y}+\mathrm{S} / 2$}

Where (Y) presents the F \& B labor force numbers in a certain state divided by the mean of thetotal manufacturing sector in the country, and (S) resulted from the formula of the F \& B manufacturing value-added in a certain state divided by the mean of total manufacturing value- added in that state. Noted that the candidate ignored the value of Tobacco, as the involved industry focuses on Food and Beverages only. Though the value-added indicates the benefits returned on both government state and the total GDP as well. 
Table 19. Food and Beverages' IQC by state, based on data of 2016.

\begin{tabular}{|c|c|c|c|c|c|c|}
\hline $\begin{array}{l}\text { State } \\
\text { Name }\end{array}$ & $\begin{array}{c}\text { F \& B manufacturing } \\
\text { portion out of total } \\
\text { manufacturing } \\
\text { sector }\end{array}$ & IQC & $\begin{array}{l}\text { Total F \& B value } \\
\text { added in Naira. } \mathbf{N}\end{array}$ & $\begin{array}{c}\text { F \& B } \\
\text { labor } \\
\text { numbers }\end{array}$ & $\begin{array}{c}(\mathbf{Y}) \\
\text { Labor } \\
\text { mean }\end{array}$ & $\begin{array}{c}(\mathbf{S}) \\
\text { VAlmean }\end{array}$ \\
\hline Abia & 14.5 & 0.50 & $1,307,693,904.38$ & 977,337 & 0.73 & 0.27535 \\
\hline Adamawa & 18.8 & 0.18 & - & 490,480 & 0.37 & 0 \\
\hline Anambra & 7.8 & 0.51 & $1,928,852,309.00$ & 808,915 & 0.60 & 0.406142 \\
\hline Abuja & 10.4 & 3.02 & $25,446,833,007.67$ & 925,026 & 0.69 & 5.358126 \\
\hline Akwa Ibom & 19.9 & 0.60 & $3,082,305,989.78$ & 725,112 & 0.54 & 0.649015 \\
\hline Bayelsa & 15.8 & 0.35 & - & 944,660 & 0.71 & 0 \\
\hline Borno & 25.8 & 0.94 & $2,505,579,149.39$ & $1,799,045$ & 1.35 & 0.527579 \\
\hline Bauchi & 8.3 & 1.28 & $5,991,015,251.95$ & $1,731,112$ & 1.29 & 1.261478 \\
\hline Benue & 16.3 & 0.72 & $3,922,029,662.75$ & 820,826 & 0.61 & 0.825829 \\
\hline Cross river & 31.1 & 0.82 & $2,835,412,894.23$ & $1,395,034$ & 1.04 & 0.597029 \\
\hline Delta & 14.8 & 0.85 & $2,588,326,909.55$ & $1,552,144$ & 1.16 & 0.545002 \\
\hline Ebonyi & 22.5 & 0.06 & - & 168,030 & 0.13 & 0 \\
\hline Ekiti & 17.1 & 0.14 & $46,965,373.97$ & 369,633 & 0.28 & 0.009889 \\
\hline Edo & 18.8 & 1.22 & $6,278,283,224.77$ & $1,503,430$ & 1.12 & 1.321965 \\
\hline Enugu & 27.3 & 0.58 & $112,518,295.31$ & $1,512,929$ & 1.13 & 0.023692 \\
\hline Gombe & 15.1 & 0.05 & - & 138,336 & 0.10 & 0 \\
\hline Imo & 13.4 & 0.90 & $2,424,629,192.60$ & $1,729,914$ & 1.29 & 0.510534 \\
\hline Jigawa & 14.5 & 0.78 & $810,117,969.78$ & $1,852,246$ & 1.39 & 0.17058 \\
\hline Kaduna & 13.6 & 1.05 & $665,501,864.21$ & $2,624,583$ & 1.96 & 0.140129 \\
\hline Kano & 13.7 & 2.21 & $14,263,251,719.69$ & $1,889,053$ & 1.41 & 3.003293 \\
\hline Katsina & 19.9 & 0.54 & \begin{tabular}{|l|}
$436,579,511.80$ \\
\end{tabular} & $1,324,416$ & 0.99 & 0.091927 \\
\hline Kebbi & 13.8 & 0.67 & $1,377,200,548.63$ & $1,401,755$ & 1.05 & 0.289986 \\
\hline Kogi & 12.8 & 0.08 & - & 225,316 & 0.17 & 0 \\
\hline Kwara & 16.1 & 0.10 & $129,520,252.80$ & 229,278 & 0.17 & 0.027272 \\
\hline Lagos & 23.4 & 8.31 & $61,332,614,472.77$ & $4,946,430$ & 3.70 & 12.91429 \\
\hline Nassarawa & 17.3 & 0.37 & $23,132,199.12$ & 992,266 & 0.74 & 0.004871 \\
\hline Niger & 18.6 & 0.07 & $53,236,323.73$ & 173,472 & 0.13 & 0.01121 \\
\hline Ogun & 18.9 & 1.78 & $8,463,917,955.18$ & $2,378,941$ & 1.78 & 1.782176 \\
\hline Ondo & 27.7 & 0.67 & $806,905,126.55$ & $1,571,835$ & 1.18 & 0.169903 \\
\hline Osun & 17.4 & 0.92 & $2,627,498,011.45$ & $1,732,540$ & 1.30 & 0.55325 \\
\hline Oyo & 26 & 2.68 & $\mid 14,342,106,384.29$ & $3,134,354$ & 2.34 & 3.019897 \\
\hline Plateau & 11.8 & 0.93 & $3,898,066,821.20$ & $1,394,723$ & 1.04 & 0.820783 \\
\hline Rivers & 24.8 & 1.05 & $4,243,010,445.42$ & $1,617,440$ & 1.21 & 0.893415 \\
\hline Sokoto & 33.8 & 0.73 & $1,036,514,426.09$ & $1,650,944$ & 1.23 & 0.21825 \\
\hline Taraba & 20.4 & 0.58 & $1,500,633,063.11$ & $1,122,514$ & 0.84 & 0.315976 \\
\hline Yobe & 14.5 & 0.46 & $100,945,181.45$ & $1,213,601$ & 0.91 & 0.021255 \\
\hline Zamfara & 17.4 & 0.27 & $1,139,354,670.84$ & 408,073 & 0.31 & 0.239904 \\
\hline Total & & - & $175,720,552,113.45$ & $49,475,743$ & -- & - \\
\hline
\end{tabular}

Source of $\mathbf{F} \&$ B manufacturing numbers: NIPC, list of food, beverages and Tobacco companies, 2016, and $\mathrm{F} \& \mathrm{~B}$ manufacturing portion out of the total manufacturing sector calculated by the candidate

Source of IQC: Formula calculated by the candidate based on NBS, Employment and labor statistics report, 2016.

Source of Food and Beverages Value added: CBN, Statistical Bulletin, section of Real Sector, 2016. 
Nigerian states can be classified to main five groups according to their portion of the total $\mathrm{F} \& \mathrm{~B}$ processing manufactories. The analysis combines with the F \& B qualitative classification using the Industrial Quantum Coefficient (IQC) and F \& B value added as per reported calculationin table (19) to be discussed as follows:

The first group includes all states that have F \& B Industrial Quantum Coefficient exceeding the total ONE, as nine states are ranked respectively as Lagos, Abuja, Oyo, Kano, Ogun, Bauchi, Edo, then Kaduna and Rivers came at the same rank. This group, as shown in Figure (16), is considered as an extraordinary group, since the main reason for making these states exceed the normal coefficient (accurate 1) is that the inputs of $F$ $\&$ B manufacturing variables are greater thanthe mean average.

Starting by Lagos state, it has historical records of industrialization especially after settled different Industrial Areas in the 1950s to facilitate the benefits of using the local materials. It considered as a center of gravity for related and unrelated industries, and it is still out of competition for different manufacturing measurements. The locational conveniences pushed the continuity of industrial localization as business services, and the infrastructure strongly strengthens the $\mathrm{F} \& \mathrm{~B}$ manufacturing quantities to participate with almost $23.4 \%$ of its total manufacturing amounts. It has been observed that Lagos presents perfectly the Mercantile Model of (Vance, 1970), especially its fourth phase started in the 1980s and continues until 2000. Since increasing the local industrialization at the backyards of seaports, and then intensively improving the merchant centers in the state that impacting positively the surrounding states as Ogun and Oyo. What makes Lagos state comes on the top of F \& B value-added with more than 61 Billion Naira is its position as a coastal port, and its earlier infrastructure development, which established in the British colonized period. The railways and ungraded road networks support the development of logistic dynamics surrounding the seaport. The IQC indicates that continuous urban development gives Lagos different opportunities to practice long experience of managing industrial estates, and other trading services to produce more. The volume of production and successful performance attracts those F \& B manufacturers in different investment scales to expand their operation in it. The IQC recorded 8.31 to isolate itself from any competition since it has the superiority of refining sugar with $70 \%$ of its total manufacturing valueadded. Its geographical location helped in imported sugarcane and other food materials. 


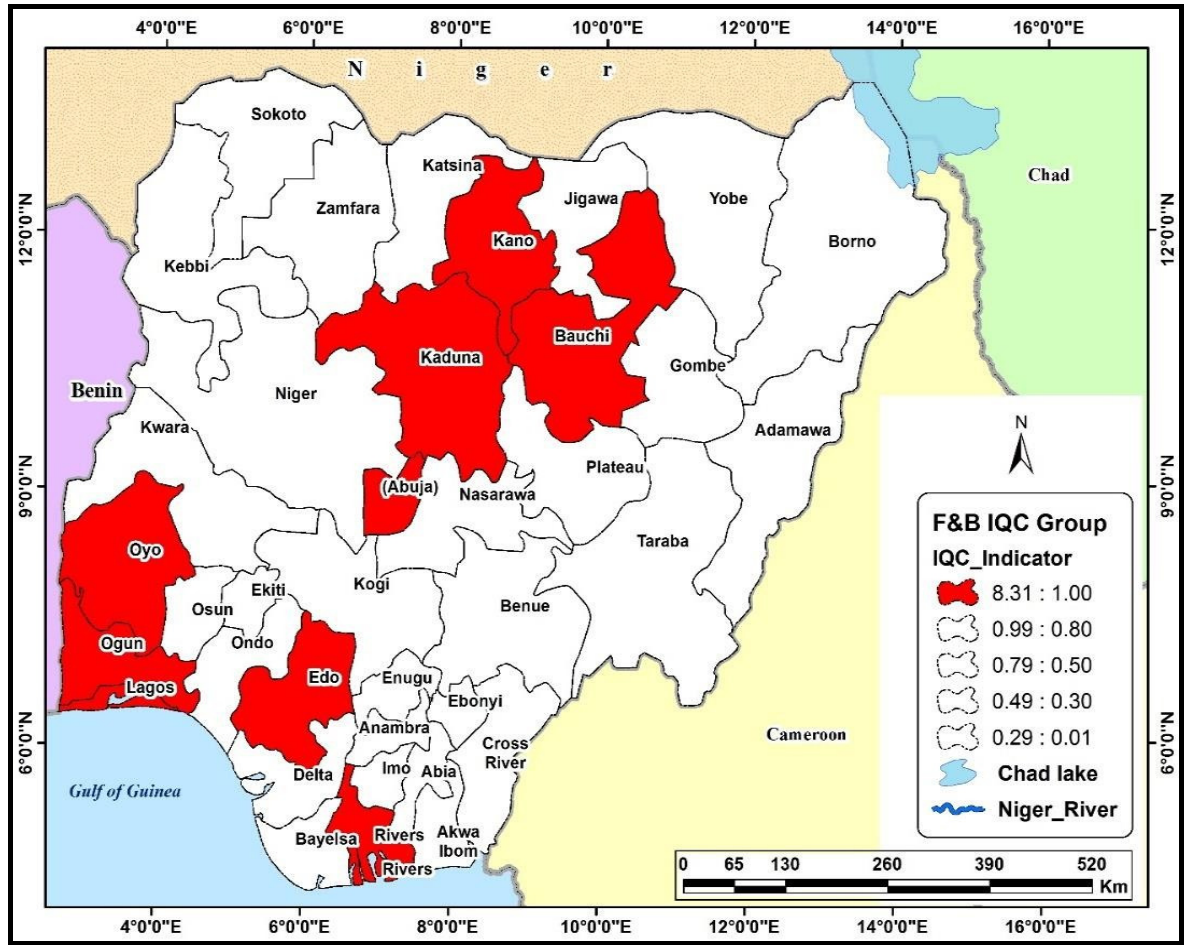

Figure 16. The First F \& B IQC Industrial Quantum Co-efficiency distribution group by state, 2016.

Source: Table (19)

According to the previous analysis conducted earlier in this chapter; $\mathrm{F}$ \& B manufacturing in Lagos produced $10 \%$ of processing editable oil, and $82 \%$ of the total Grain Mills. The related food manufacturing developed accordingly such as pasta, noodles, bakeries, and beverages, as it witnessed increasing in its total F \& B Sub-sector value-added. About $51 \%$ of the red meat processing and preserving performed in Lagos, $20 \%$ of the Nigerian dairy processing value-added, and $12 \%$ of cocoa gained from the large-scale investors locating at Apapa industrial estate. While it has five industrial estates, the F \& B concentrates in Ikeja, and Apapa industrial estates leaving the rest for occupied by the other industrial Sub-sectors. Although the governmental policy in 2012 bans imported most of that food manufacturing inputs, the F \& B's value-added performed from Lagos did not affect that much. Both industrial estates are including only large and middle-size investments especially those operating sugar, pasta, and grains processing that pushed up Lagos'svalue-added paralleled with cost reduction. 
Geographically, Ogun state is a border state and located neighboring to Lagos state, which gives its advantages regarding F \& B development. The F $\&$ B manufacturing enterprises occupied $18.9 \%$ of the total manufacturing units at the state. However, it has only two industrial estates as Ota and Opic, it has superiority in the manufacturing of beverages rather than food, as it participates with $41 \%$ of the total beverage plants. Ogun state offers infrastructure facilities within their industrial estates that upsurge foodprocessing value added to go beyond 8.4 Billion Naira. The developed analysis presents IQC of 1.78 as an indicator given that four main foodprocessing operations increased the state' VA to upgrade the F \& B Subsector in the state to participate in theGDP of 2015. The numbers of the food manufacturing units increased, especially the operations of meat processing and preservation as protein processing, and almost $13 \%$ of the fish processes are existing at the state out of the total country's units. Moreover, the manufacturing of grain millsforms a share of $14 \%$, and the cocoa processing consists of $25 \%$ of the state's F \& B units with considering $29 \%$ as a portion of vegetable, fruit processing and preservation contribution. The percentage of tomato-paste operation units show $15 \%$ of the national Sub-class enterprises, whichwas manufactured in Ota and Opic industrial estates.

The geographical location of Ogun state between Lagos and Oyo states support to upgrade the extension of the infrastructure including transportation affected the maximizing of $\mathrm{F} \& \mathrm{~B}$ value added in third of them. The official statistics reported that Ogun state has a shortage in processing and preserving of the red meat, and dairy. The neighboring Oyo state to Ogun aids its manufacturing of F \& B Sub-sector. Its F \& B hits nearly $26 \%$ of the total manufacturing active units, and its IQC pointed 2.68. The state has four industrial estates attracting investments with a large scale, and it seems that the state government efficiently used its rural productions.

The majority of $\mathrm{F} \& \mathrm{~B}$ firms in the state indicate an increase in the percentage of manufacturing capacity utilized in 2015 , which reflects the reasonable of food production increased VA to reach more than 14.34 Billion Naira. The majority of F \& B manufactories at the state go to flour mills and refining vegetable oils. Oyo state comes in the third rank of the Food Sub-sector VA, the cocoa and confectionery processing share hit $49 \%$ out of the total mentioned share of $26 \%$, as the local farm produced cocoa in large amounts as shown earlier. The state also participates with fish processing and preservation, and the manufacturing of grain mills performing in the state roughly $11 \%$, while meat processing and preserving perform 14\%. It has been realized that the Multiple- nuclei model (Chauncy 
Harris and Edward Ullman, 1945) clearly reflected the F \& B industrial localization, among others, at third of them.

Although the F \& B manufacturing in Abuja consisted of $10.4 \%$ of the total industrial plants to present a high portion of food operation units as a Federal Capital, the Food and Beverages IQC indicated merely 3.02. The share of manufacturing units including four food Sub-sectors participating in this growth are meat processing and preserving with $21 \%$, manufacturing of Grain Mills Products by $9 \%$, Beverages with about $8 \%$, and $3 \%$ of the total manufacturing of dairy products respectively. The high IQC pointer is probably a consequence of a certain political reason as pushing the industrial business to allocate in the Federal Capital during the 1990s. As a result, it attracted the richest local investors and governmental companies to establish their units in. While the F \& B manufacturing labor numbers were less than one million, the VA was little above 25.44 Billion Naira for the high amount of invested capitals in 2015.

The industry in Kano state revised to the 1930s, it was the main manufacturing centerof the Caliphate but was too populated to develop vast cotton plantations. Hence cotton started to be imported from Zaria (Y.B. Usman, 1974, pp. 130-136). The cotton industry attracted the other related industries, that included the processing of vegetable oils, and cottonseed that occupied $15 \%$ of the Nigerian F \& B value added in 2015 . The state included huge numbers of $\mathrm{F} \& \mathrm{~B}$ factories that make it share by $13.7 \%$ of the total Nigerian F \& B manufactories. This share may present a small portion compared by the other states especially in Kano. This included the share of vegetable oilsat $15 \%$, and cottonseed which occupied the same share of the Nigerian F \& B units. The local share involved $11 \%$ processing and preserving of the red meat, 5\% manufacturing of the grain mills products, and roughly $10 \%$ of the refining sugar preformed units in the country.

Some researchers have seen that this percentage reflects the quantities that do not actually affect the volume of production. Its IQC announced 2.21 since the mean exceeded the normal average. Its $\mathrm{F} \& \mathrm{~B}$ manufacturing production performed high VA reached about 14.263 Billion Naira. The value-added controlled by sugar refining performing in the state, which affected the growth of its local bakery and confectionery processing to increase its total share in GDP of 2015. Kano state included huge numbers of F \& B factories that make it share by $13.7 \%$ of the total Nigerian F \& B manufactories. 
The industry in Kano state revised to the 1930s, and developed in the 1970s, for textile development, which attracted the other related industries. Those related businesses included the processing of vegetable oils, and cottonseed that occupied $15 \%$ of the Nigerian F \& B value-added.Because of the strategic importance, population and industrious nature of its people, Kano is blessed with a number of small-scale industries. These industries cover several areas of manufacturing but a greater number of them is in food and agro-allied (Munir Abba Dandago, Earnest Chukwusoro Igwe, 2011, pp. 131-136).

Kaduna state followed Kano at the locational level, which gives it the advantage to encourage F \& B investment to allocate there. The developed analysis reported IQC of the F \& B as 1.05 to reflect again the F \& B crowded units in the state. Those manufacturing entities participated with the F \& B operators produced a total VA as almost 665.5 Million Naira. In 2015 , the F \& B operating units share value of $13.6 \%$ of the total manufacturing operators in the state. The main activities topped by $13 \%$ of the national production of vegetable and animal oils, vegetable and fruits processing and preservation, soft drinks, and juices (Federal Ministry of Industry, Trade and Investment report, 2018, pp. 35-76).

Furthermore, it holds only $3 \%$ of breweries enterprises despite the official records of fish processing and preservation witnessed deprive, as well as manufacturing of Grain Mills Products located at the state. The population density in Kaduna state reached 49 residences per square kilometer, and this F \& B Sub-categories as numbers bakeries find proper labor and consumer markets rather than any other categories. The volume of food crop productions and the labor market at the state supporting the industry to increase to hit that VA, while the portion of manufacturing units is not that much.

Bauchi state is neighbored by Kaduna and Kano states both forming a backyard to Bauchi, which is the highest northern populated and industrial density state. It seems that with consideration of the local food crops cultivating in those neighboring states, the investors utilizedthem to develop their business. Bauchi recorded an IQC of 1.28 pushed by the total valueadded of 5.9 billion Naira. The $\mathrm{F} \& \mathrm{~B}$ manufacturing units participated with $8.3 \%$ only out of state' manufacturing enterprises. At the same time, the market demand in those backyard states attracted different investors of food manufacturing to establish their factories nearby that golden agglomerated dynamic markets. A clear example has been observed in the spatial analysis 
of thosethree states is realized Bauchi state has a shortage of four main F \& B Sub-categories manufacturing, and three of those F \& B categories afforded in Kaduna state. Moreover, the two main food manufacturing operated units at Plateau state is totally absent from the Bauchi manufacturing formal records as a grain mill and dairy products. While Kaduna industrial locations witnessed nonattendance of meat processing \& preservation and grain mill, the manufacturing units at Bauchi found their place unintentionally.

Edo and Rivers states both are located at the south part of the country, but the IQC indicates 1.22 for Edo state. Again, the value-added of F \& B in Edo hits about 6.27 Billion Naira comes out $18.8 \%$ of the total industrial units at the state. The analysis detected that the state witnessed growth in the edible oil processing operators between 2011 and 2015, as the utilizing capacity increased from investments of palm kernel and palm oil. This came along with its total production of dairy products as recorded about $81 \%$ of the national production. The dairy processes and preservation VA pushed up after the collaboration between the main dairy processors in Nigeria and local suppliers as backward integration to increase the local supplying resources. Furthermore, the state's production of the national vegetable and animal oils recorded around $45 \%$ of this category, and about $9 \%$ of the national share of the grain mill processing. That gives the state a rational causeto perform that amount of VA of the F \& B Sub-sector.

Rivers state marked a total VA of its F \& B activated manufacturing units more than 4.24 Billion Naira. The superiority of F \& B manufacturing at Rivers state resulted due to the advancednumbers of the fish processing and preservation products units, and labor forces that contributed by $18 \%$ of the total state's manufacturing performance. The total F \& B manufacturing active unitsparticipating by $24.8 \%$, and their production performance allows the state to rank at the seventh stage of total F \& B outputs on the national level. This may return to the other food business activities at the Port Harcourt, especially the salt refining operations, as the geometric coastline which encourages the fishing operations. Moreover, the other segment of the food manufacturing VA amended to its performance of the local units of vegetable refining oil as reached $20 \%$ of the national operations. The main factors are revised to processing of the food various categories, such as increasing manufacturing the grain mills products which shared about $8 \%$ of the cassava and wheat flour milling activated plants performed on the macro level. 
Different small F \& B factories initiated specifically for processing cassava flour, paddy rice, and tomato paste, particularly in the southern part of the country. At the last few years the manufacturing of pasta/macaroni and other flour products were developed that encouraging flourSub-sector business to sustain a high record of VA according to the manufacturing utilized the capacity of that sector between 2010 and 2015. Rivers state characterized by salt processing ratherthan the beverages Sub-sector. In this respect, it is important to mention that the value-added of this Sub-sector was promoted by the beverages operations since it dominating the total units and preformed high productivities between 2013 and 2015.

According to the developed analysis, the observation marked geographically, the first group includes two parts of states dominating the up normal F \& B manufacturing IQC mean and they consisting of neighboring states. Three are agglomerated in the southwestern part of the country led by Lagos state, and another is located in the northern part led by Kano state. These industrial conglomerations playing a vital role in balancing the pattern of $\mathrm{F} \& \mathrm{~B}$ manufacturing distribution throughout the country. In fact, Lagos, Ogun, and Oyo consisting a triumvirate hitting a compound

F \& B value-added of almost 84 Billion Naira, although the rest of the states in this group recordedF \& B value-added about 56.65 Billion Naira with an IQC exceeding 12 time and above five times the main average respectively.

As per observed in southern states, the F \& B manufacturers were concentrating on theprocessing and preservation of cash crops like palm oil, sugarcane, cocoa, and process the stable tuber such as cassava among other food inputs. The food manufacturing of these cash crops increased both the total value-added and the income of the local labor force. Regarding the northernstates, the sub-sector value-added earned from pulses, grain milling, and processing of cottonseeds and groundnuts, while the southern party gain their growth of VA from refining sugar, mainly, andprocessing of cash crops such as cassava and cocoa furthermore fishing operations.

The second group presents six states that indicated IQC between 0.99 and 0.80 involved Borno, Plateau, Osun, Imo, Delta, and Cross River respectively. Spatially, this group reflects an extreme example of the first group model, as its states are scattered throughout the country. Noted that some of the states in this group have the same case, geographically, except Borno and Cross River states as will discuss below. 
Starting with Borno state, as the highest IQC marked in the second group to record 0.94 with a value-added exceeded 2.5 Billion Naira. The state is one of the Border States that shared Cross-border Road-networks with the other territories. It is rich with a variety of food crops, and the main city is located at the central location of the state. As mentioned before, its fortune of the food crops concentrates on the grain and pulses including maize. It has a rich water table resourced by the Lake of Chad pushing its food manufacturing units to provide more. Such a case gathering investors to sustain the demand of the local market and the other neighboring countries. Its total F \& B operation units reached $25.8 \%$, and the state has an essential infrastructure, built by military especially in Maiduguri city for security issues, and developed by time to maintain the volume ofoil presses and millers in Maiduguri which exceeds all cities in the state. The F \& B manufacturing at the state is limited to Nigerian Bottling Company, and as statistical records segmented nonattendance of the vegetable and animal oil's manufacturing.

Plateau state segmented and IQC of 0.93 for the favor of its VA as recorded by almost 3.89 Billion Naira. The state gathered $11.8 \%$ of its industrial units to F \& B manufacturing enterprises. Plateau state was built on a highland which was a proper place to foreign investors and residential at this latitude of the country. Consequently, the states gained high VA particularly from dairy, and manufacturing of grain mill products which increased by the new entrance of noodles and pasta manufacturing units as $6 \%$ of its total F \& B Sub-sector. Nigerian bottling company also runs a new branch at the state, flour mills with related operations, and meat processing and preservation as distribution mentioned before. The state is a backyard of both Kaduna, Kano and Bauchi states,since all are sorted in the first group. It seems that, however, food industries must distribute throughout the country, the states that recorded outstanding IQC impacts their neighbouring states in the light of manufacturing operations.

Osun state reflects the same case of Plateau, as a courtyard of the first group marked IQC records. Concerning the IQC of F \& B manufactures as 0.92 resulted from only $17.4 \%$ of the total manufacturers at the state. The Food manufacturing VA went beyond 2.6 Billion, it has well- established infrastructure facilities within their industrial estates to upsurge the food processing VA. It has noted that Vance's merchant model expanded to different centers in Nigeria surrounding Lagos as a star state to expand the manufacturing VA and commercial centers. The state governmental instruction also aimed to upgrade numbers of the food manufacturers units 
especially protein processing, such as fish production and preservation. State's location served this target as a backyard state to most fish producing states, as the best site to such manufacturing operations. That answered the increasing portion of the state in the total Nigerian fish-manufacturing categorycontribution as shaped by $15 \%$ of the total.

The F \& B manufacturing units participated with $13.4 \%$ in Imo state out of the total manufacturing to record a VA of 2.242 Billion Naira. The IQC gauge announced 0.85 with the attendance of Soft-drinks operators, bakeries and confectionery, and meat processing running units. The ongoing business supported by the nearest locations of raw materials came from Imo and neighbored states. While almost one-third of industrial operators at Cross rivers state, $31.1 \%$, are presented $\mathrm{F} \& \mathrm{~B}$ manufacturing enterprises, they resulted VA of 2.835 Billion Naira. The IQC of the F \& B at the sates revealed 0.82 . The state produced different food cash crops such as palm oil, cocoa, and cassava that increased the variable of labors who participated in IQC. Delta state participates with an IQC of 0.85 , and its Food manufactories contributed by $13.4 \%$ of its total manufactories units. Those units produced a total value-added hit almost 2.588 Billion Naira, while Delta hasn't a beverage operating processors. The official formal statistics recorded two main food categories at the state as vegetable and fisheries that are operated by intensive labors as both depended on the initial phase and also highly needed by the local market.

The third group including eleven states remarked IQC indicators range between 0.78 and 0.50, as listed ascending as Jigawa, Sokoto, Benue, Kebbi, Ondo, Akwa-Ibom, Traba, Enugu, Katsina, Anambra, and Abia respectively. Jigawa state shares a boundary with Kano state which is the second population, market, pole throughout the country. F \& B operators share $14.5 \%$ of its total industrial firms to add around 810 million Naira as F \& B' value-added. Its IQC figured 0.78 for its cash crops processing operations further the local meat and poultry processing and preservation productions. The F \& B business units increased its production to supply both Kano and the other neighbored states.

Sokoto state argued the IQC of 0.73 as a result of its operating F \& B business that pushed by its local upgrading of infrastructure and water table. The state recorded a high volume of tomato-pasta and other vegetable and fruits processing and preservation units. The $F \& B$, portion of manufacturing firms reached $33.8 \%$ to argue a VA of more than 1.036 billion Naira. The state is an official path of the old Sahara traded stream, 
which developed continually its market with high demand for F \& B' production.

Benue state sorted at the third rank in this group for its IQC as 0.72 , which resulted from $16.3 \%$ of its total industrial running units, F \& B shares. The grain procedures dominating the food manufacturing units plus the vegetable and fruits processing and preservation with only two breweries enterprises to result in a VA estimated by 3.92 billion Naira. The state is located at the Benue River, one of the main Niger River's streams controlled by moderated climate, which enriches it by a high crop production that encourages investors to locate their business for food manufacturing there.

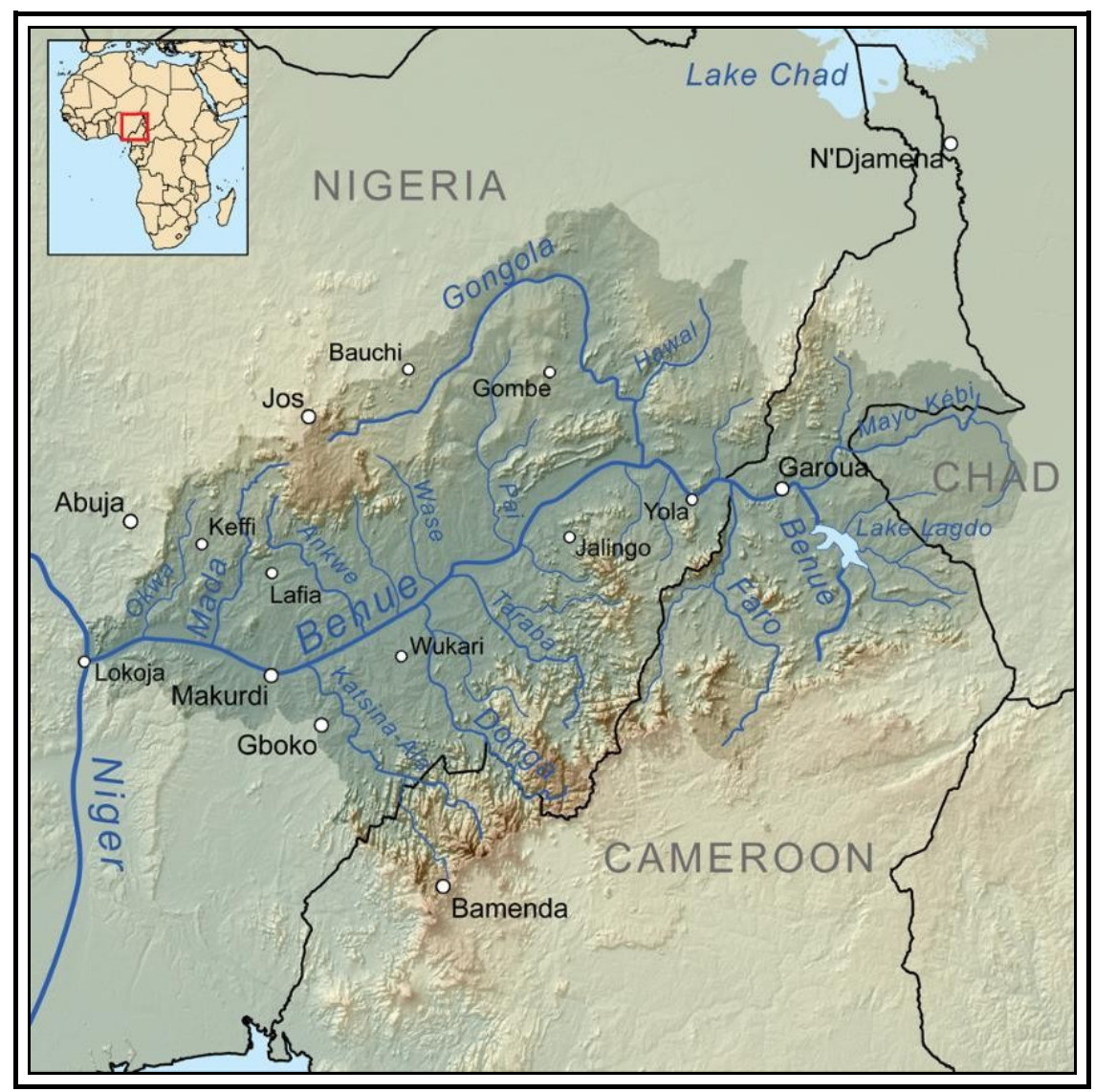

Figure 17. Benue state locations and water-streams penetrate it to feed the water table.

Source: www.revolvy.com/page/Benue-River?smv=26664674, accessed 8 October, 2019, 3:12 PM. 
Kabbi state recorded an IQC indicator of 0.67. Since it located in the northwestern part of the country, its water table supported to produce high local food crop production to utilize it to operate fruits and vegetable processing and preservation units that contributed with bottling water operators by $13.8 \%$. The total F \& B manufacturing VA went beyond 1.377 billion Naira. Most of the food production VA presented from processing the food cash crops produced at the state as cotton, cottonseed pressing, sesame oil, and groundnuts as well. While Ondo state has the same portion of Kabbi state of IQC as 0.67, its F \& B's manufacturing portion hits 27.7 out of its total manufacturing units. Its F \& B's share seems to contribute highly among other manufacturing sectors, but its VA did not exceed 807 million Naira. The state located at the southern part of the country, and accurately neighbored by Osun and Lagos states that supported it by the extended infrastructure facilities. Despite Akwa Ibom also located in the coastal zone with limited food crop production resources, its IQC reported 0.60 for the favor of its F \& B's number of units that share $19.9 \%$. The value-added estimated by more than 3 billion Naira, and the manufacturing supported by the hydropower supply plant. Food manufacturing in the state relay on three main categories as processing and preservation of fish, large scale investment in pasta and noodles, and vegetable processing. The neighboured state is Abia with IQC shows 0.50 , and F \& B's units' form $14.5 \%$ participated in 2015 by a total of 1,307 billion Naira as VA. The food manufacturing there relies on dairy processing, and vegetable processing and preservation, as well as grain processing and breweries. Regarding Katsina state which located at the far north of the country beside both Kano and Zamfara with the lower value-added of F \& B in that group, it presents only 436 Billion Naira. Its IQC pointed 0.54 which is not the squatted value in this group, while its F \& B manufacturing entities present the same valued as Akwa Ibom state. The state full of flour mill operators and also has three beverages processors utilizing its resources of vegetable and fruits grain production, and also water table to increase their profits.

Although Taraba and Enugu states are marked the same IQC pointer as 0.58 , they have a different share of F \& B manufacturing firms as $20.4 \%$ and $27.3 \%$ respectively. The area of both states are varied, and the $\mathrm{F} \& \mathrm{~B}$ raw productions. The area of Taraba state is almost counting five times of Enugu state, but its F \& B manufacturing value-added reached 1,500 billion Naira. The state has a boundary with the Republic of Cameroon, and its topography dominated by high lands. The state experienced civil conflicts that issued the industrial investments there. Despite F \& B manufacturing enterprises at Enugu state contributed by 112 billion Naira as VA, its location at Niger 
River's bank gives it rich facilities served the manufacturing investors as waterway transportation and provided it by a drinkable water source. Anambra neighboring Enugu state withan IQC indicator of 0.51 , and the F \& B manufacturing Sub-sector marked only $7.8 \%$ of its total industrial operators to add about 1,928.8 billion Naira. This value resulted from the processing and preservation of vegetables, fruits, and grains since the state witnessing an absence of breweries operations. The high amount of valueadded was not came from manufacturing full process only, but also caused by the cocoa preparation.

The fourth group includes only three states, and their IQC of F \& B manufacturers remarked a range between 0.49 and 0.30 . Those states are separated geographically as Yobe at the far north to show an indicator of 0.46 , followed by Nasarawa state which reported 0.37, and finally Bayelsa state which stated 0.35 in the coastal zone.

Yobe state yielded on the groundnuts and its food crops producing high volume according to its environmental conditions. The Food manufacturing relay on cattle market, cottonseed pressing oil, beans and groundnuts among others to come with a share of $14.5 \%$ of the total manufacturing operators at the state level to produce VA of almost 100.9 billion Naira. Regarding Nasarawa state its IQC index pointed out 0.37 , as consider as a middle scale concentration of F \& B industries. Since it participates with $17.3 \%$ out of its total manufacturing enterprises to devote with VA of 23 million Naira.

The official records documented the holistic domination of Nigeria bottling company at the state plus food operators. What increased its F \& B' value-added is its high production of cash cropsduring the year, which needs intensive labors for the initial phase as preparation. Bayelsa state came at the last rank in this group for its IQC marker as 0.35 , despite its F \& B manufacturers granted $15.8 \%$ of its industrial running business. The state experienced null VA of $F$ \& $B$ units since a clear absence of $F$ \& $B$ manufacturers. Thus the portion of $15.8 \%$ granted for its food crops and fishing preparation to sale in the local state market as fresh products.

The fifth group comprised seven states like Zamfara, Adamawa, Kwara, Kogi, Niger, Ebonyi, and Gombe respectively, as if sorted ascending by their IQC indicator. There are four main neighbored states, as three of them sharing the Niger River water as Kawara, Niger, and Kogi states that are in the western part of the country. Two other states are located at the eastern part as side by side as Gombe and Adamawa states leaving the 
Ebonyi state contributing with its share of figures, but not geographically. The F \& B's IQC of this group extends between 0.27 and 0.05 respectively since all participated by less than $30 \%$ as F \& B manufacturing operators share of the total industrial enterprises.

Spatially, Zamfara state locates in the north part meanwhile, its food crop production contributing by its local water table supplying the manufacturing firms by needed fundamental materials. The $\mathrm{F} \& \mathrm{~B}$ manufacturing sector at the state dominated by beverages processing, and food operators produced vegetables, fruits, and oil pressing manufacturing. Those participated with $17.4 \%$ out of total industrial enterprises, which increased the value added to present almost 1,139 billion Naira. For its climate condition, and its location, the F \& B manufacturing did not find investment support to upgrade the scale to the level of a large scale that leads its IQC to record only 0.27 . While the Niger state shared a short boundary with Zamfara state, it's F \& B manufacturing units' joint by $18.6 \%$. Niger state has shown lower IQC for its F \& B running the industrial business in 2015, for its sugar manufacturing closing unit, as it has the sugar refining capacity enables it to increase its food processing value-added from 53.2 million Naira to hit more than one billion Naira as if returned to operate again. Its running F \& B operation firms indicate only 0.07 as IQC pointer.

Kwara state also shares one boarder-side with Niger state, and with Kogi state which belongsto this group. The IQC indicator marked 0.10 and its F \& B value-added in 2015 estimated by almost 129,5 million Naira. Kwara includes different types of F \& B manufacturing classes as flour mills,starch, and fish preparation and preservation among others. The state also highly produced petrochemical productions like plastic. The F \& B running capacity units share about $16.1 \%$ out of its total industrial capacity. In this regard it should mention the integration occurred between the foods industrial units of both Niger and Kwara state. Dangote group established its business as flour mill at both in 2010, and gained the BUA sugar refining manufactory as mentioned before atthe Niger state with large investments to increase its utilizing capacity and manufacturing profits. This example clarifies a clear role of the large investment to do the integration performance of different food manufacturing units to promote the variety of food demand. Nigerian Breweries also increased its investments in Kwara since 2012 as mentioned before, and both Kwara and Niger states are processing sugar which increased their manufacturing VA. 
Kogi state also shared a border with both Niger and Kwara, and its IQC ranged between both as indicated by 0.08 . While it's local F \& B industrial share never exceeded $12.8 \%$, its VA did not mention in any official records. The food crop production recorded high value, and its initial phase as preparation. Similarly, Ebonyi, Gombe, and Adamawa states as third of them operating food crops post-harvested phase with underemployment forces to record IQC as initial industrial phase as $0.06,0.05$, and 0.18 respectively.

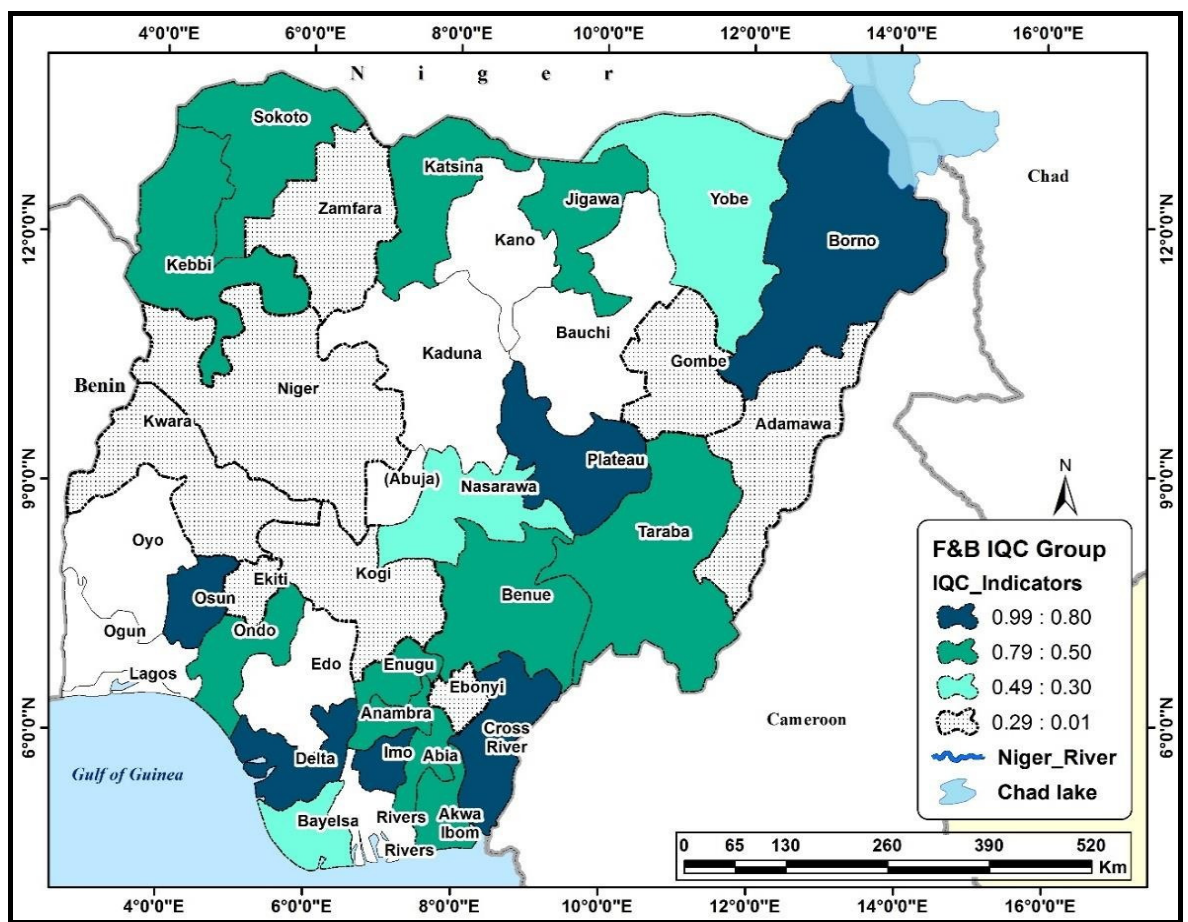

Figure 18. F \& B Industrial Quantum Co-efficiency distribution groups ranked (below accurate One), 2016.

Source: Table (19).

During the IQC indicators tour combined with the F \& B's value added, and its share out of total states' industrial enterprises; the spatial analysis clarifies the unbalanced distribution of industrial entities in 2015. This came with the historical pattern, between 2010 and 2015 of manufacturing capacity utilized of each F \& B manufacturing Sub-classes throughout the country. This combine a stable ground of SWOT analysis and suggest a solution, but that will not occurs without a clear view of the industrial policies and its pivotal role in this issue. 


\subsubsection{Food industrial quantum weight analysis}

The Food industrial manufactories in Nigeria have the various spatial pattern, and to clarify this distribution and the reason behind, they can be classified to groups as follows:

The first group includes Lagos state only for its superiority of holding the highest amount of the food industrial units plus the volume of their production and business integrity. Logos state by itself has eleven industrial estates and parks that facilitating all needs to food industries. It witnessed historical records of logistics improvement and industrial services. In attendance of $820 \mathrm{~F} \& \mathrm{~B}$ manufacturers, Lagos centralizes the F \& B industrial integration, and the rest of the states economically. The cost of transportation or transferred imported food inputs to the distanced state increased the total overhead cost, which made certain investors establish pasta and noodles factories at the state. Lagos and other coastal states are golden examples of adapted Mercantile Model, (Vance, 1970) as the best site selection to reduce the costs of imported products, especiallywith the same location to practically implement one of the main characteristics of F \& B industries as nearby one another. However, in Lagos this theory is not binding, two large-scale foreign investors preferred to locate at Ogun state near the border with Lagos. In presence of food and beverages agglomeration in Lagos, different companies maximized their production.

This attracts related operators to locate in the same state regardless of the business size. The best example is sugar refinery, hence around $75 \%$ of the total national refiners, and about $51 \%$ ofthe confectionaries are located at Lagos. Sugar manufacturing supplies all beverages,confectionery, and pharmaceutical manufacturing throughout the country. Although Lagos state has its share of threats like high pollution, slums further extra damaged infrastructure in its ancient areas like North-East parts, the state is a special case of integrated F \& B manufacturing. Lagos will be difficult to repeat particularly in Nigeria before a long time, as about 693 are operating F \& B business out of a total of 820 manufacturing firms. In detailed, it reported 141 factories producingeditable oil, and 127 firms are processing beverages.

The second group consists of six states and the third group also. Both groups include numbers of the food processors ranged between 24 and 74 operators. However, the industrial incentives arenot equally distributed in the twelve states, they still have the advantage edge as establishing at the industrial estates and industrial parks. This to empower the competition between local governments of those states to attract investors again. 
Regarding the coefficient numbers of the food firms in those states, there are no reasonable reasons leading to sustain their continuity except for the incentives they got from each location they are occupied. The food manufacturing Sub-category data analysis represents that both Ogun and Oyo states have a spatial food manufacturing competition, and little integration between them had been recorded. Oyo state has processors of chocolate, canned, and dried food, while Ogun state has not. At the same time, Ogun state has the superiority of producing snacks and dairy products that are not operated in Oyo state yet.

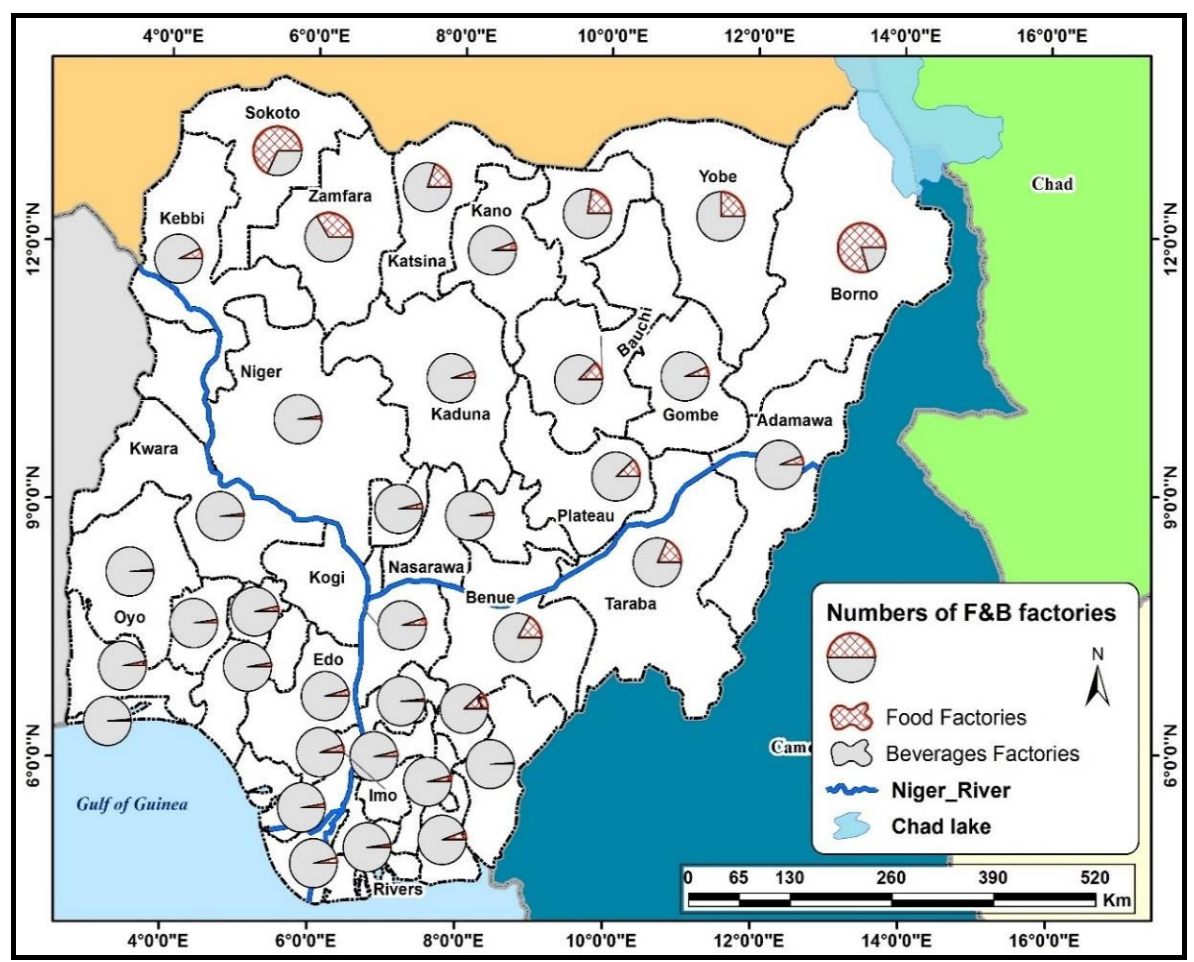

Figure 19. Distribution of food and beverages numbers of factories, 015 Source: NBS, and CBN, 2016.

Similarly, Abia and Rivers state, as both have no candy, dried food, sugar refinery, palm kernel oil, and flour millers processing. While River state has an advantage as experienced manufacturing of bean products, snacks, canned food, frozen vegetables producing, and egg production, Abia state practiced dairy, grains, and palm oil processing and preservation. Both can feed one another in an industrial supply chain by integrating with 
different industrial phases, as grain processing in Abia state can feed the snacks production operated in the River state. Another dimension of the nearby spatial integration illustrates in the transport facilities, as using their internal network with each other. In this regard, it is a must to mention that the fourth of the previous states are depending on most of their production on sugar refinery, flour mills, and edible oils that are processed in Lagos state. Abuja by itself has $55 \mathrm{~F} \& \mathrm{~B}$ factories, and Zamfara holds a huge amount of grain millers within other vegetable and fruits processors to record 48 different F \& B operators.

Six states belonging to the third group have F \& B manufacturing firms ranged between 24 and 36 factories per state. It seems that the agglomerated food processing units in the same zone attractthe same sector investments. It clarifies in the agglomerated five states in the south part of the country. Those states are share administration boundaries located in the same geographical zone as Edo, Delta, Enugu, Anambra and Imo states. The analysis presents Kano state on the top list of the two groups. Despite Kano state had joined the third group, its main contribution to food industries came from its food additives production as essential for different food categories production. Kano state still has a defect in eleven food manufacturing Sub-categories, while the state has an advantage in both frozen and fresh food processing.

The nature of the main function of the state as industrial activities domination its lifestyle. Nevertheless, the surrounded states have superiority in producing pulses among the other cereals crops, the state missing the resources of bean crops. The documented statistics missed the bean processing and also starch, grain, canned and dried food, and chocolate processing and preservations operating companies. Although Anambra and Delta state witness defects in various food productions as chocolate, food additives, vegetable oils, and palm oil processing, Edo and Enugu states have a shortage in the manufacturing of bean products, canned food, frozen vegetables, egg production, grain milling, and starch productions. Nevertheless, Imo state testifies the highest number of edible oil pressing, it comes to share the same shortage as the same categories as Edo and Enugu, and Anambra states occasionally. Those groups of five states have the same food manufacturing facilities, as different Industrial parks and estates were established still have a shortage of developing more food manufactories that integrated between them. It notesthat, the F \& B operation units in this group are less than three in each list F \& B category and it seems that they all have the same conditions of settling industrial units. 
The fourth group includes six states, and each one has numbers of food manufacturing operators ranged between 6 and 23 units. Those states are scattered geographically through the country, and have similarity in categorized the scarcity of the food manufacturing Sub-sector. The record shows evidence of the total shortage in producing dried food, large scale bakeries, and grain processing, while the states have large amounts of postharvested crops as maize and sorghum among the other cereals. Sokoto state participates by one firm of bean processing and preservation, and tomato paste within other vegetable and fruit preservation, but Ondo state marked the highest poultry processing and preservation operators.

The fifth group consists of eighteen states that have less than five factories per state. Four states market total drop in F \& B operation units as Bauchi, Kebi, Taraba, and Yobe states. Eight of them completely recorded droop in food manufacturing number of units in specific products, such as candy and snacks productions, canned food, fresh food, frozen vegetables, dairy processing, further Starch processing, sugar refinery, palm kernel oil processing, and flour millers. Those eight are Adamawa, Akwa Ibom, Bayelsa, Bornu, Benue, Ebonyi, Ekiti, and Gombe states. Regarding the numbers of factories, it has been noted that four states have only one food operator as Niger, Katsina, Gombe, and Ebonyi states, while three states have three factories as Adamawa, Bayelsa and Nassarawa states for each.

\section{Conclusion}

The F \& B industrial structure changed again between 2009 and 2015, but its share in GDP almost still the same. The beverage manufacturing still dominated the industrial capital because of the environmental conditions throughout the country. One-third of food industries are located in the rural areas and the rest located in both urban areas as cities or nearby the ports as industrial parks and estates.

The IQC indicated seven states as extraordinary of both invested capital and labors, which reflected the dynamo of industrial estates' facilitations and local attraction of each state to appeal the investment in F \& B sector. Eight states were exceeded the IQC of food industries indicator for different reasons. Spatially their locations were not agglomerate as it was expected, and those states did not contain the largest amount of $\mathrm{F} \& \mathrm{~B}$ manufacturing numbers. The foreign capital investments have not controlled those states, except in Lagos state, and that expanding of foreign capital investments form a vital threat faced the F \& B manufacturing. The mentioned states distributed throughout the Nigerian territory, and hold large and middle manufacturing investment scales that indicate those states are growth poles. 